La etología puede relacionarse con la estructura genética

de una población: Chaetodipus siccus un caso de estudio

\title{
Ethology may be related to the genetic structure of a population: Chaetodipus siccus as a study case
}

\author{
Eduardo Felipe Aguilera-Miller ${ }^{1 *}$
}

\begin{abstract}
${ }^{1}$ Centro de Investigaciones Biológicas del Noroeste. Instituto Politécnico Nacional 195, La Paz 23090. Baja California Sur, México. E-mail: relupin@gmail.com (EAM).
\end{abstract}

Philopatry is a biological trait observed in a wide variety of zoological taxa. It is considered as the basis of social behavior in rodents as well as a driver of spatial distribution of individuals. Females are typically philopatric, whereby they have access to resources to breed their offspring. This philopatric tendency is partly responsible for the genetic structuring in the natural populations of mammals. Heteromyid rodents conform complex communities and the agonistic interactions among them are common. Aggressiveness is the way to establish dominance hierarchies. By setting a hierarchy, dominant individuals have priority access to critical resources. Chaetodipus siccus is an heteromyid endemic to the Baja California peninsula, distributed across an area of $\sim 270 \mathrm{~km}^{2}$, where a particular pattern of high variation of matrilineal lineages has been observed. The presence of multiple spatially segregated matrilineal lineages has been proposed, reinforced by the aggressive nature of the species, which leads to limited panmixia within the range of $C$. siccus. To test this hypothesis, a statistically parsimonious haplotype network study was conducted using matrilineal markers and behavioral experiments of intra- and interspecific dominance. Thirty four localities were surveyed throughout the $C$. siccus distribution range to capture specimens $(n=143)$ for the statistically parsimonious network. Muscle tissue was used for DNA extraction, and fragments of Cytb and COI genes were sequenced. To study intraspecific and interspecific dominance, ethological experiments were conducted between females under different conditions. For this purpose, 52 adult females of $C$. siccus and five adult females of $C$. arenarius, $C$. ammophilus, $C$. spinatus and C. rudinoris were captured alive and maintained in captivity. Encounters took place inside neutral arenas every other night. Individuals were housed individually in social cages. Fifty three haplotypes of Cytb and 15 of COI were identified from 143 C. siccus individuals. A high variety of private haplotypes was observed ( 31 for Cytb and 5 for COI). The presence of a dominant individual over another was observed in all conditions in the intraspecific and interspecific dominance experiments. Dominant females were statistically more aggressive than subordinate females $(p<0.001)$, and C. siccus dominated over the other species. A marked genetic structure was observed, with a considerable presence of private haplotypes. It is considered that genetic structure occurs when subpopulations are at least partially isolated from each other. There are no appreciable physical barriers within the distribution range of the species. For this reason, it is suggested that ethological interactions rather than geographical features may limit gene flow within the population of $C$. siccus. Structures with an unusual number of haplotypes in small geographical areas, as in C. siccus, have been previously recognized for other mammal species. It is argued that this pattern is the result of a philopatric character of females; this behavior restricts gene flow between areas. The existence of several geographically restricted matrilineal lineages suggests that females do not disperse, but remain within a very small geographic area. This points directly to the presence of philopatry in females. Agonistic behaviors are the means through which an individual maintains its hierarchy over others, defining its preferential access to resources. it's the extremely aggressive nature and a territorial behavior of females of $C$. siccus have resulted in the segregation of matrilineal lineages.

Key words: agonistic encounters; gene flow; Heteromyidae; hierarchies of dominance; matrilines.

La filopatría, rasgo biológico presente en una amplia variedad de taxa zoológicos, es considerada como base del comportamiento social entre roedores. También es promotor importante de la distribución espacial de los individuos. Las hembras son típicamente filopátricas, característica que les confiere acceso a los recursos necesarios para criar a su progenie. Esta tendencia filopátrica es en parte, responsable de la estructuración genética en poblaciones naturales de mamíferos. Los heterómidos conforman comunidades complejas y las interacciones agonísticas entre éstos es un patrón generalizado. La agresividad es el medio por el cual se establecen jerarquías de dominancia; gracias a éstas, los individuos dominantes obtienen acceso prioritario a recursos. Chaetodipus siccus es endémico de la península de Baja California, distribuido en un área de $\sim 270 \mathrm{~km}^{2}$ y en el cual se ha identificado un peculiar patrón de diversidad de 
linajes matrilineales. Por esto, se tiene la hipótesis de la presencia de múltiples linajes matrilineales segregados espacialmente y promovidos por la naturaleza agresiva de la espacie, lo que limita la panmixia dentro de su área de distribución. Para probar esta hipótesis se realizó una red de haplotipos estadísticamente parsimoniosa empleando marcadores de herencia materna y experimentos etológicos de dominancia a nivel intra e interespecífico. Se visitaron 34 localidades para capturar individuos de C. siccus $(n=143)$ para el análisis de la red estadísticamente parsimoniosa. Se empleó tejido muscular para la extracción de DNA y se secuenciaron fragmentos de Cytb y COI. Para estudiar la dominancia intra e interespecífica, se condujeron experimentos etológicos bajo diversas condiciones entre hembras. Para esto, 52 hembras de C. siccus y cinco hembras de C. arenarius, C. ammophilus, C. spinatus y C. rudinoris fueron capturadas vivas y mantenidas en cautiverio. Los encuentros tuvieron lugar en arenas neutrales, cada tercera noche. Los individuos fueron alojados individualmente dentro de cajas sociales. Se identificaron 53 haplotipos de Cytb y 15 de COI a partir de 143 individuos de C. siccus. Se observó una considerable cantidad de haplotipos únicos (31 para Cytb y 5 para COI). La presencia de un individuo dominante y uno subordinado fue observada a través de las diferentes condiciones evaluadas durante los experimentos etológicos de dominancia intra e interespecífica. Las hembras dominantes fueron estadísticamente más agresivas que las subordinadas $(P<0.001)$, incluso, C. siccus dominó a las demás especies. Se observó una marcada estructura genética con la presencia de varios haplotipos únicos. Se considera que tal estructura se presenta cuando las subpoblaciones están aisladas entre ellas, al menos parcialmente. Dentro del área de distribución de la especie no existen barreras físicas apreciables. Es por esto que las interacciones etológicas entre individuos, más que las características geográficas del hábitat, pueden ser las responsables del flujo limitado de genes, dentro de la población de $C$. siccus. Estructuras con un inusual número de haplotipos distribuidos en áreas geográficas pequeñas, como el caso de C. siccus, han sido observadas previamente en otras poblaciones de mamíferos. Se argumenta que este patrón resulta del carácter filopátrico entre hembras, conducta que restringe el flujo genético entre áreas. La existencia de linajes matrilineales restringidos geográficamente propone que las hembras no se dispersan y permanecen en pequeñas áreas geográficas. Esto apunta directamente a la presencia de filopatría femenina. Los comportamientos agonísticos son el medio por el cual un individuo mantiene su jerarquía ante otros, lo que define su acceso preferencial a los recursos. En las hembras de C. siccus, su naturaleza extremadamente agresiva y su comportamiento territorial ha resultado en la segregación espacial de múltiples haplotipos matrilineales.

(c) 2016 Asociación Mexicana de Mastozoología, www.mastozoologiamexicana.org

\section{Introducción}

A medida que los individuos maduran, éstos tienen la opción de dispersarse o retrasar la dispersión y permanecer en el mismo sitio en el que nacieron, a esto se le denomina filopatría (Solomon 2003). Aunque gran interés en el estudio de la filopatría se debe a que dicha conducta es considerada como la base del comportamiento social entre los roedores (Michener 1983; Waser y Jones 1983; Solomon 2003; Clutton-Brock y Lukas 2012), también puede influir en la distribución espacial de individuos (Solomon y Getz 1997; Blumstein y Armitage 1999; Lacey 2000) y de linajes, promovidos principalmente por las hembras (Chesser 1991; Dixon 2011). El estudio de la filopatría se ha abordado de diferentes maneras según el autor o el grupo de organismos estudiado. Debido a sus varias connotaciones, se utilizará la idea propuesta por Waser y Jones (1983) que hace referencia a la permanencia de un individuo, en su lugar de nacimiento, aún después de haber alcanzado la madurez e independencia parental. Entre los mamíferos, las hembras son típicamente filopátricas (Chesser 1991; Dixon 2011), ya que de esta manera tienen acceso a sitios de refugio y de forrajeo previamente conocidos y posiblemente heredados (McGuire et al. 1993), esenciales para la crianza de su progenie (Greenwood 1980).

Los roedores de la familia Heteromyidae son un grupo de mamíferos en los que se ha estudiado la evolución de diversos patrones de comportamiento (e. g. Randall 1984a, $\underline{b}$; Bleich y Price 1995; Newmark y Jenkins 2000; Winters y Waser 2003; Cooper y Randall 2007; Meshriy et al. 2011). Este grupo de roedores se distribuye principalmente en los ambientes áridos de Norteamérica (Vaughan et al. 2000). Las condiciones imperantes en estos ambientes los han forzado a adquirir estrategias tanto fisiológicas como de comportamiento para poder sobrevivir a ciclos de precipitación extrema seguidos de largos periodos de sequía (Vander-Wall 1990). Es por esto que la obtención y defensa del recurso alimenticio son centrales para estos organismos. 
Las comunidades de heterómidos pueden ser muy complejas, debido a que se ha registrado la coexistencia de hasta seis especies diferentes (Brown y Harney 1993; Vaughan et al. 2000), por lo que la defensa de territorios entre conespecíficos y especies simpátricas es un patrón generalizado (Eisenberg 1963; Jones 1993; Shier y Randall 2007). Los heterómidos representan un grupo de especies solitarias, pero tienen sistemas sociales sólidos y establecen familiaridad con individuos estrechamente relacionados (Cooper y Randall 2007). El sobrelapamiento de territorios es un fenómeno común que contribuye a la organización social y promueve la tolerancia (Shier y Randall 2007; Vázquez y Álvarez-Castañeda 2011), de esta manera se evitan enfrentamientos y agresiones que pueden tener un alto costo energético en temporadas de intensa competencia por recursos (Silk 2007; Holekamp et al. 2012). No obstante, existe la evidencia de comportamientos agresivos entre heterómidos (Eisenberg 1963; Randall 1993). La agresión es el medio por el cual se establecen jerarquías de dominancia, con las que se puede mediar la prioridad de acceso a los recursos, de esta forma, las hembras dominantes podrán monopolizar sitios de crianza o forrajeo y permanecer filopátricas (Newmark y Jenkins 2000). Los experimentos de agresividad se han utilizado frecuentemente en investigaciones de interacciones agonísticas entre roedores (Harper y Batzli 1997; Johannesen et al. 2002; Shier y Randall 2007) y entre musarañas (Oleinichenko 2000; Rychlik y Zwolak 2006). La agresión parece ser una adaptación primaria para hacer frente a la competencia (Moynihan 1998); así, la cantidad de conductas agonísticas específicas dirigidas hacia un competidor deberán reflejar el grado de competencia verdadera (MacArthur 1972; Perri y Randall 1999). Destacan dos estudios que abordan las jerarquías de dominancia entre heterómidos. En el primero se abordaron las relaciones de dominancia entre especies simpátricas (Dipodomys stephensi y D. agilis) mediante encuentros agonísticos en el laboratorio, con el propósito de determinar si dichas conductas previenen el uso del mismo hábitat (Bleich y Price 1995). Dipodomys stephensi demostró ser dominante y excluir a D. agilis, con lo que los autores concluyen que el dominio interespecífico puede ser un factor importante en el uso diferencial del hábitat. En el segundo estudio se examinó la mediación de interacciones intraespecíficas en $D$. heermanni y se probó si individuos no conocidos entre sí establecen una jerarquía de dominancia con la posterior disminución de conductas agresivas (Shier y Randall 2007). Los resultados sugieren que las jerarquías de dominancia pueden ser el medio para mitigar la agresión.

Los procesos poblacionales primarios como la especiación (Doebeli y Dieckmann 2003), el flujo genético (Hedrick 2001) y las asociaciones entre individuos (Wang et al. 2011) afectan y reflejan patrones de estructuración genética. El análisis de las variaciones en el DNA mitocondrial de los individuos ha contribuido significativamente en la identificación de estructura genética en las poblaciones naturales (Avise 2000). Los estudios socio-genéticos han establecido que la mayoría de los mamíferos se caracterizan por exhibir un sistema poligínico con la presencia de hembras filopátricas y la asociación de éstas en grupos matrilineales estrechamente emparentados (Clutton-Brock 1989; Kappeler et al. 2002). Sin embargo, se ha observado que las especies del género Chaetodipus presentan un sistema social en donde los adultos son solitarios (Genoways y Brown 1993; Jones 1993; Nowak 1999). La historia evolutiva de los heterómidos se basa en sólidas hipótesis que encuentran sustento en la información obtenida de varios marcadores moleculares (Neiswenter y Riddle 2010).

El ratón de abazones arenoso C. siccus (Osgood 1907) es parte del complejo arenarius, el cual también incluye a C. arenarius (Merriam 1894) y C. ammophilus (Roth 1976; Álvarez-Castañeda y Rios 2011; Rios y Álvarez-Castañeda 2013). C. siccus, originalmente descrito como subespecie de C. arenarius (Patton y Álvarez-Castañeda 1999), se encuentra distribuido exclusivamente dentro de la cuenca de Los Planes, en un área de $\sim 270 \mathrm{~km}^{2}$ y en una pequeña parte al sur de Isla Cerralvo, en el Estado de Baja California Sur, México. Por otro lado, a partir de la revisión del complejo arenarius (Álvarez-Castañeda y Rios 2011) fue posible identificar varios haplotipos matrilineales en la población insular de $C$. siccus; de aquí que su carácter endémico, los patrones genéticos únicos que presenta (Álvarez-Castañeda y Rios 2011) y el potencial comportamiento filopátrico 
de sus hembras le confieren un gran interés en términos de conservación. Es por ello que se tiene la hipótesis de la presencia de múltiples linajes matrilineales espacialmente segregados y promovidos por la naturaleza agresiva de la especie. Lo que conlleva a panmixia limitada en el área de distribución de $C$. siccus. Para probar estas hipótesis se llevó a cabo una red estadísticamente parsimoniosa empleando dos marcadores matrilineales (Cytb y COI) y experimentos etológicos de dominancia intraespecífica e interespecífica.

\section{Materiales y métodos}

Red estadísticamente parsimoniosa y estructura genética. Se visitaron 34 localidades a través del intervalo de distribución de C. siccus entre septiembre y noviembre de 2010 (Anexo 1A). Para la captura de los especímenes se empleó la técnica de transecto lineal. En cada transecto (uno por localidad) se colocaron 60 trampas para roedor tipo Sherman, con una separación de $10 \mathrm{~m}$ entre cada trampa. Los animales fueron manipulados siguiendo en todo momento las recomendaciones de la American Society of Mammalogists (Sikes et al. 2011). Los especímenes voucher, así como las muestras de tejido muscular (almacenadas en tubos con etanol al $96 \%$ ), fueron depositados en la Colección de Mamíferos del Centro de Investigaciones Biológicas del Noroeste (CIB). Dicha colección se encuentra registrada debidamente ante SEMARNAT (BCS MAM 085 0899). El detalle de los ejemplares voucher, georreferencia de las localidades y los números de acceso a GenBank se encuentra en el Anexo 1B y $C$.

Para la extracción del DNA genómico, la amplificación del DNA (Cytb $=800$ pb; $\mathrm{COI}=650$ pb) mediante la Reacción en Cadena de la Polimerasa (PCR), la secuenciación y la medición de variación genética en $C$. siccus, se implementaron los protocolos y los análisis descritos en ÁlvarezCastañeda y Rios (2011).

La relación entre haplotipos de Cytb y COI fue inferida utilizando parsimonia estadística (Templeton et al. 1992) mediante TCS 2.8 (Clement et al. 2000). TCS estima las relaciones haplotídicas para niveles bajos de divergencia y ofrece una posible explicación estadística $(P=0.95)$ para todas las conexiones. Los índices de diversidad $(h)$, diversidad nucleotídica $(\pi)$ y la media de las diferencias entre pares de haplotipos (Mean number of pairwise differences; Tajima 1993) fueron inferidos por medio de ARLEQUIN 3.0 (Excoffier et al. 2005). La media de las diferencias entre pares de haplotipos se estima a partir del número de mutaciones ocurridas desde la divergencia entre cada par de haplotipos; la varianza total, estimada entre la frecuencia de un haplotipo y el tamaño de muestra, asume la no recombinación entre sitios y neutralidad selectiva (Tajima 1993).

Experimentos etológicos de dominancia. Para el estudio de dominancia entre hembras, se llevaron a cabo experimentos etológicos, bajo diferentes condiciones y a partir de encuentros entre diadas, dentro de arenas neutrales. Este tipo de experimentos se ha utilizado frecuentemente en investigaciones etológicas de agresividad entre roedores (Harper y Batzli 1997; Johannesen et al. 2002; Shier y Randall 2007).

\section{Dominancia intraespecífica}

Primero. Dominancia directa entre hembras de C. siccus. Con este experimento se pretendió demostrar que existe menos agresión entre hembras familiarizadas de la misma localidad de captura que entre hembras no familiarizadas de diferente localidad de captura y las condiciones fueron: $a$ ) entre hembras de la misma localidad de captura, $b$ ) entre hembras de la misma localidad de captura con proceso de familiarización, $c$ ) entre hembras de diferente localidad de captura y $d$ ) entre hembras de diferente localidad de captura con proceso de familiarización.

Segundo. Dominancia a través del tiempo entre hembras de $C$. siccus. Con este experimento se pretendió demostrar que la relación dominante-subordinado deberá permanecer constante a lo largo del tiempo. Para este experimento se consideraron las mismas condiciones descritas para el primer experimento de dominancia directa, ya que ambos fueron llevados a la par. 
Tercero. Dominancia con base en la defensa del recurso alimenticio (Rychlik y Zwolak 2006) entre hembras de $C$. siccus. Con este experimento se pretendió demostrar que la dominancia se ejerce por el control del recurso, independientemente de su utilidad inmediata. Que las conductas agonísticas se presentarán entre hembras, sin existir una agresión teórica hacia el macho, ya que al ser quien se dispersa, no representa una amenaza hacia las hembras. Las condiciones fueron las siguientes: a) ambas hembras en ayuno de $24 \mathrm{~h}, b$ ) ambas hembras alimentadas ad libitum, c) la dominante alimentada ad libitum y la subordinada en ayuno de $24 \mathrm{~h}$. y d) ambas hembras alimentadas ad libitum, con la presencia de un macho. Se proporcionaron $2 \mathrm{~g}$ de hojuelas de avena como recurso a defender (aproximadamente $10 \%$ del peso corporal de los individuos).

\section{Dominancia interespecífica}

Cuarto. Dominancia entre hembras de C. siccus y hembras de cuatro especies del género Chaetodipus a partir de la defensa del recurso alimenticio (Rychlik y Zwolak 2006). Con este experimento se pretendió demostrar que la dominancia interespecífica está en función de la masa corporal. Las especies enfrentadas con C. siccus fueron C. arenarius, C. ammophilus, C. spinatus y C. rudinoris. Los porcentajes de masa corporal en gramos de las cuatro especies con respecto a la de $C$. siccus fueron 105, 111, 131 y $181 \%$, respectivamente. En este experimento se evaluaron las mismas condiciones $(a, b$ y $c)$ descritas para el tercer experimento de dominancia con base en la defensa del recurso alimenticio entre hembras, excepto que en éste no se consideró la condición donde el macho estuvo presente.

Procedimientos generales. Para los tres primeros experimentos de dominancia intraespecífica se capturaron 32 hembras adultas y ocho machos adultos de C. siccus en las localidades A y B separadas por $5 \mathrm{~km}$ (Figura 1). Dichas capturas se llevaron a cabo en septiembre de 2012 y junio de 2013. Para el experimento de dominancia interespecífica, el cuarto, se capturaron 20 hembras adultas de $C$. siccus de la localidad A, entre abril y junio de 2015 y cinco hembras adultas de $C$. arenarius, C. spinatus, C. ammophilus y C. rudinoris (Anexo 1D).

Debido a que el cautiverio y el aislamiento promueven la agresividad entre los roedores, los ejemplares fueron alojados en cajas sociales (Yoerg 1999; Yoerg y Shier 2000). Las cajas sociales tiene la característica de ser de acrílico transparente $(20 \times 20 \times 20 \mathrm{~cm})$ con dos pequeños orificios en la base. De esta manera las hembras tienen oportunidad de intercambio visual, auditivo y olfativo. Cada hembra permaneció en la misma caja y con el mismo vecino durante el experimento. El conjunto de las características mencionadas anteriormente permitió llevar a cabo el proceso de familiarización entre individuos. Los machos fueron alojados en cajas sociales diferentes a las de las hembras.

Encuentros. Los encuentros se llevaron al cabo cada tercera noche, dentro de cajas de triplay (62 x $62 \times 30 \mathrm{~cm}$ ) colocadas sobre la tierra en una locación al aire libre dentro de las instalaciones del CIB. Una partición de madera dividió cada caja en partes iguales, manteniendo a los individuos separados durante 10 min en los que exploraron el área antes de cada encuentro (Bleich y Price 1995; Yoerg y Shier 2000; Shier y Randall 2007). Posteriormente se removió la partición e inició el encuentro, el cual tuvo una duración de $10 \mathrm{~min}$. Los encuentros fueron grabados con cámaras de visión nocturna para evitar que la presencia del espectador influyera en el resultado de las interacciones entre los individuos durante la prueba. Posteriormente se analizaron los videos de manera manual, incluso repitiendo algunas escenas, para la identificación y codificación de conductas agonísticas, toma de los tiempos, duración y frecuencia de las mismas, según la metodología especificada a continuación. Una vez que concluyeron los encuentros de cada noche, los ratones fueron devueltos a su respectiva caja social.

Análisis de datos. Se identificaron los comportamientos agonísticos presentados por los individuos de acuerdo a Shier y Randall (2007). Los valores asignados a los comportamientos agonísticos fueron: 1 (huida), 2 (movimiento), 3 (acercamiento), 4 (que se revuelca en la arena), 5 (olfateo), 6 (persecución), 7 (estocada), 8 (ataque) y 9 (pelea). Los valores bajos $(1,2,3$ ) reflejan comportamientos sumisos mientras que los valores altos $(4,5,6,7,8,9)$ se refieren a comportamientos agresivos. 


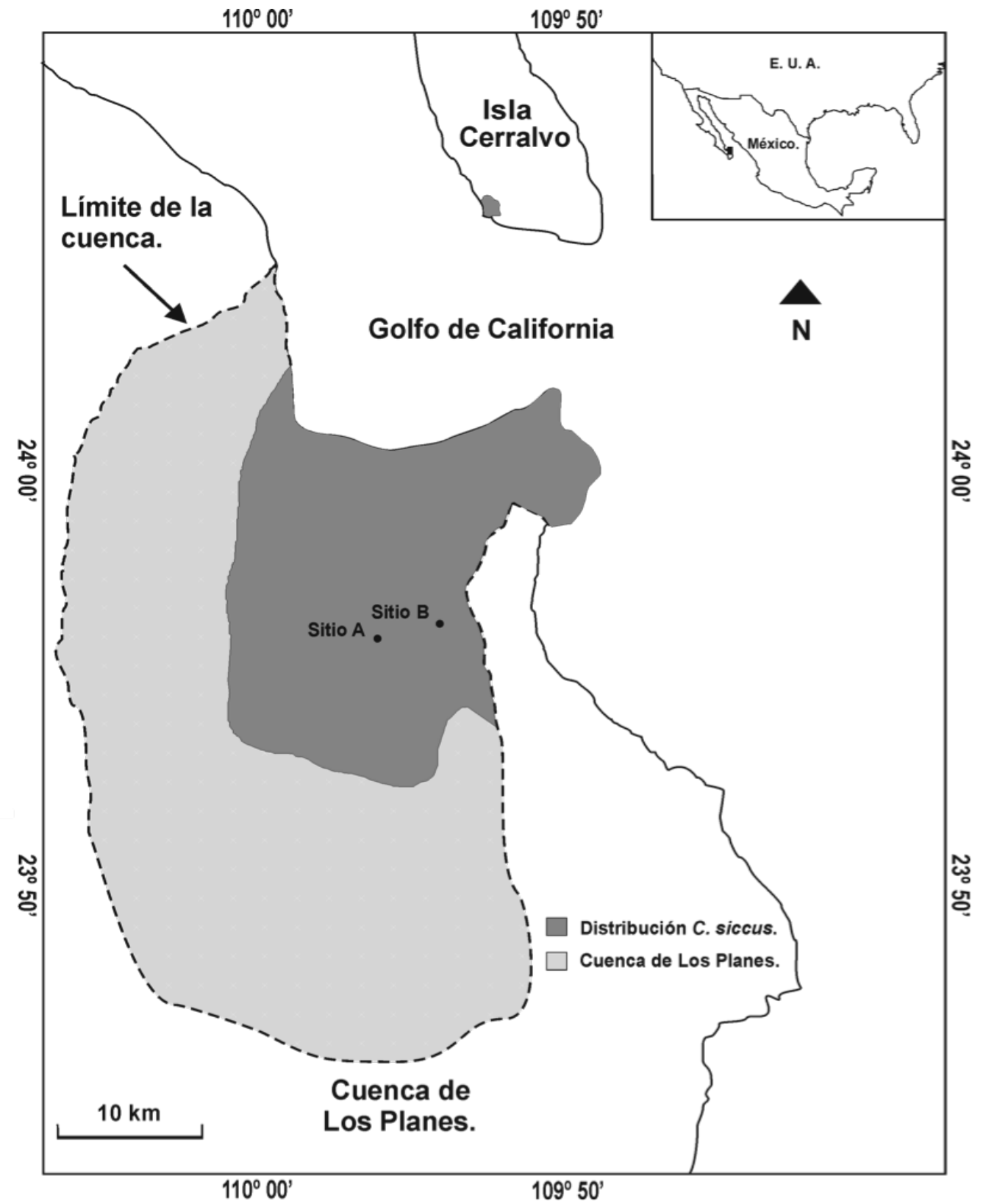

Figura 1. Área de distribución y sitios de captura (A y B) de las hembras de Chaetodipus siccus empleadas para los experimentos etológicos de dominancia (mapa modificado de Álvarez-Castañeda y Rios 2011).

Los valores presentados por cada diada de hembras en cada una de las condiciones de cada experimento fueron sumados para integrar matrices de dominancia. La ocurrencia de cualquier comportamiento agresivo de un individuo seguido de un comportamiento sumiso por parte del otro, permitió resolver la relación dominante-subordinado en cada encuentro de cada condición (Shier y Randall 2007). Los datos de cada condición expresaron la acción del individuo dominante y la reacción del individuo subordinado, obteniendo así datos pareados. Se compararon las medianas de los valores de agresividad / sumisión de los individuos dominante y subordinado para cada condición por separado mediante la prueba de signos de Wilcoxon (Wilcoxon 1945). Para identificar diferencias en las masas corporales en gramos entre $C$. siccus y las cuatro especies con las que fue enfrentada en el cuarto experimento (dominancia interespecífica), se realizó un análisis de varianza (ANOVA) de una vía. Los análisis estadísticos fueron realizados con el software STATISTICA v.8.0 (Weiss 2007). 


\section{Resultados}

Red estadísticamente parsimoniosa y estructura genética. Chaetodipus siccus fue observado en las 34 localidades visitadas (Anexo 1A). Se identificaron 53 haplotipos a partir de un fragmento de $800 \mathrm{pb}$ de Cytb (índices de diversidad: $h=0.943 \pm 0.009 ; \pi=0.005 \pm 0.002$ ) y 15 haplotipos a partir de un fragmento de $650 \mathrm{pb}$ de COI (índices de diversidad: $h=0.628 \pm 0.039 ; \pi=0.004 \pm 0.002$ ) entre 143 ejemplares examinados (con un máximo de cinco ejemplares por localidad).

La red estadísticamente parsimoniosa de Cytb $(n=53 ; 800$ pb) tiene un máximo de 14 mutaciones y 31 haplotipos (58.5\%) fueron únicos, restringiéndose su presencia a una localidad (Figura 2; Anexo 1B), aunque la distancia entre localidades es $<1.7 \mathrm{~km}$. La media de las diferencias entre pares de haplotipos de Cytb fue de $\mu=4.23$ y de COI fue de $\mu=3.14$. La red estadísticamente parsimoniosa de $\mathrm{COI}(n=15 ; 650 \mathrm{pb})$ tiene un máximo de 18 mutaciones y cinco haplotipos (35.3 $\%$ registrados en una sola localidad (Anexo 1C; no se muestra figura).

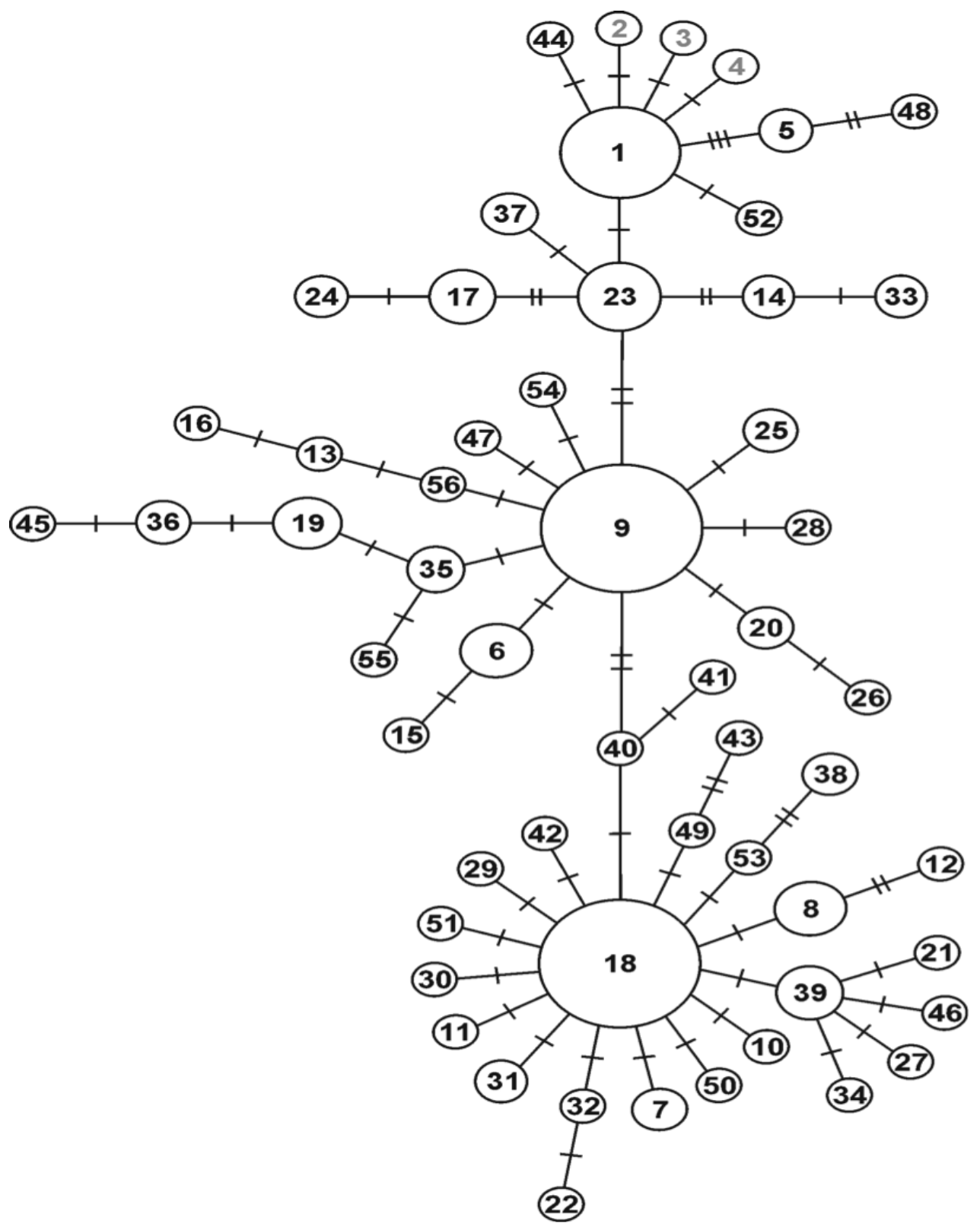

Figura 2. Red estadísticamente parsimoniosa de Cytb para 800 pb. El tamaño de los círculos corresponde a número de secuencias que sustentan a cada haplotipo. Los haplotipos 2, 3 y 4 distribuidos en Isla Cerralvo (Álvarez-Castañeda y Rios 2011) se incluyeron en la red pero no fueron tomados en cuenta para el presente estudio. 
Dominancia intraespecífica. Los encuentros agonísticos fueron usualmente momentáneos (1 - 2 s); nunca resultaron en heridas físicas apreciables. Los análisis se basaron en los datos obtenidos después de seis encuentros de ocho diadas de hembras de $C$. siccus para cada condición $(a, b, c$ y $d)$ del primero y segundo experimentos, y después de cuatro encuentros de ocho diadas de $C$. siccus para cada condición $(a, b, c$ y $d)$ del tercer experimento. En los tres experimentos de dominancia intraespecífica, primero (directa), segundo (a través del tiempo) y tercero (con base en la defensa del recurso alimenticio) se identificó la dominancia de un individuo sobre otro subordinado desde el primer encuentro $(P<0.001)$, en todas las condiciones de cada experimento (Tabla 1).

En las diferentes condiciones del primero y segundo experimento, en los que se evaluó el proceso de familiarización, no se observó cambio en las medianas (diferencia de medianas = 5, $P<0.001$ ) de los comportamientos del individuo dominante y subordinado (Tabla 1). Durante el segundo experimento, la dominancia de un individuo sobre otro subordinado permaneció constante a lo largo de seis encuentros $(P<0.001$; Tabla 1$)$.

En el primer experimento (dominancia directa) y tercero (dominancia con base en la defensa del recurso alimenticio) el individuo dominante mostró un intervalo de comportamientos mayor, a diferencia del individuo subordinado, limitándose a comportamientos sumisos (Figura 3 y 4 , respectivamente).

Los comportamientos más frecuentes del individuo dominante fueron conductas agresivas, conformando el $88 \%$ (primer experimento) y el $95 \%$ (segundo experimento). Los comportamientos más frecuentes del individuo subordinado fueron conductas de sumisión conformando el $98 \%$ en ambos.

$1 a$

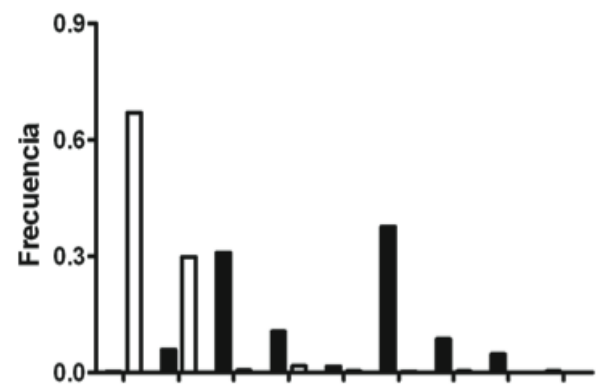

1c

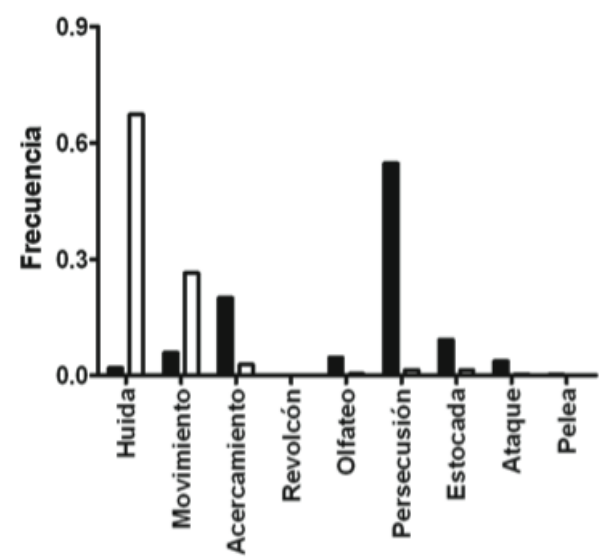

1b

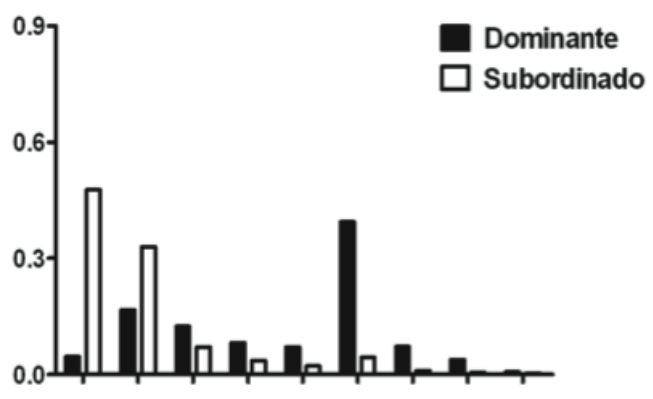

$1 d$

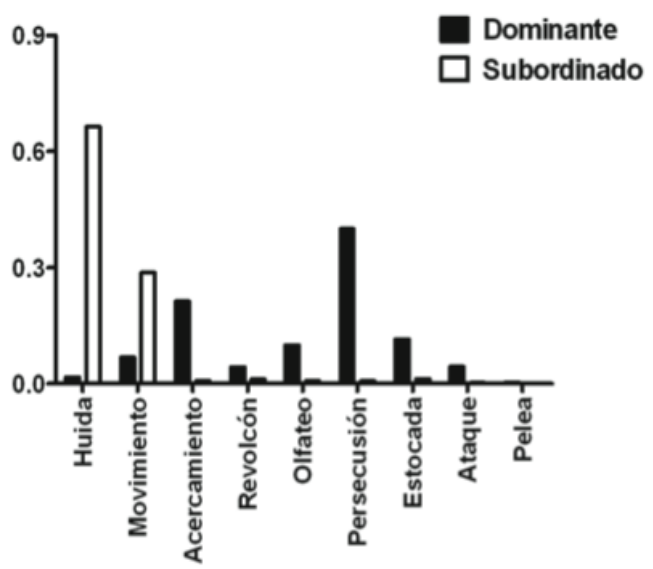

Figura 3. Frecuencia de comportamientos del individuo dominante (barras negras) y del individuo subordinado (barras blancas) durante las condiciones del experimento 1 ( $a$ : dominancia directa / misma localidad de captura; $b$ : dominancia con proceso de familiarización /misma localidad de captura; c: dominancia directa / diferente localidad de captura; $d$ : dominancia con proceso de familiarización / diferente localidad de captura. 
$3 a$

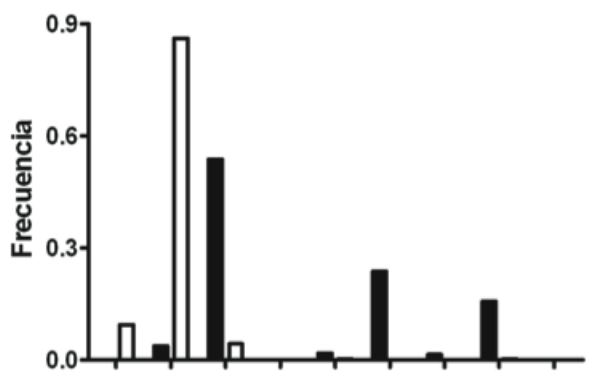

3c

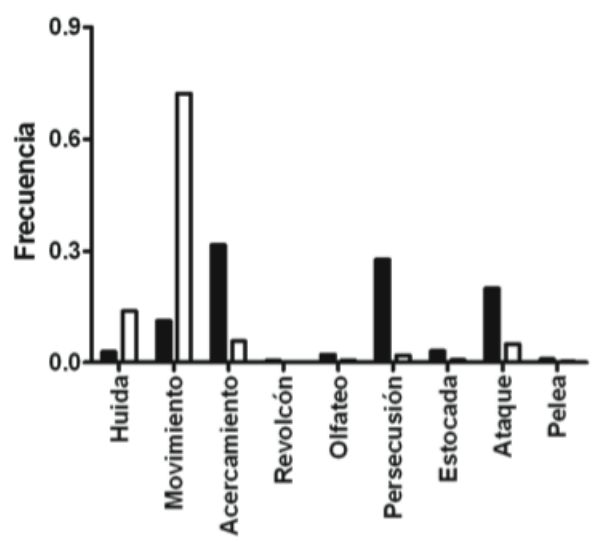

$3 \mathbf{b}$

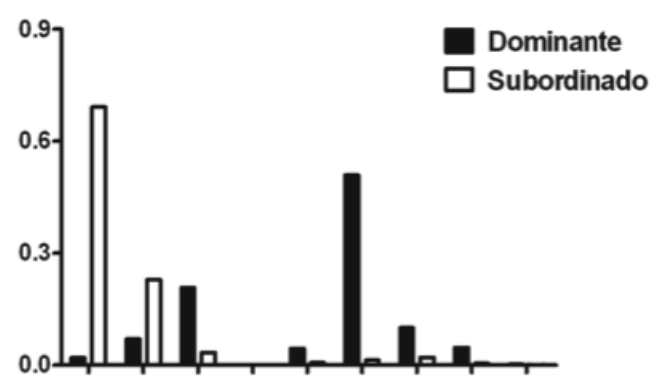

$3 d$

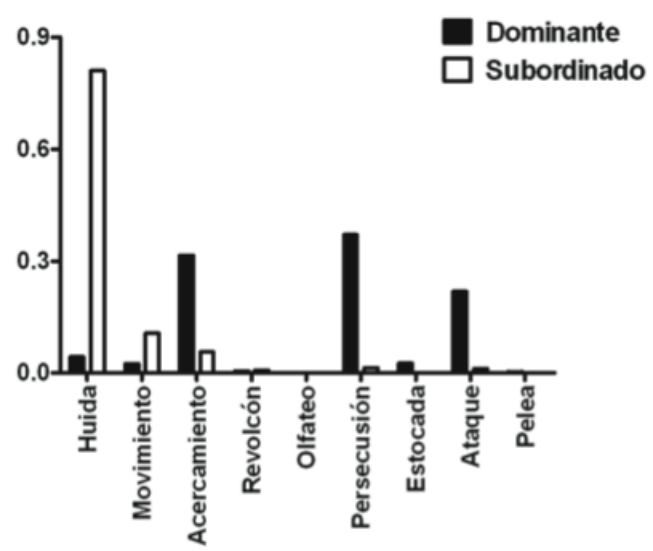

Figura 4. Frecuencia de comportamientos del individuo dominantes (barras negras) y del individuo subordinado (barras blancas) durante las condiciones del experimento 3 ( $a$ : hembras en ayuno de 24 horas; $b$ : hembras alimentadas ad libitum; $c$ : hembra dominante alimentada ad libitum / hembra subordinada en ayuno de 24 horas; $d$ : hembras alimentadas ad libitum con un macho presente (comportamientos del macho no incluidos).

En el tercer experimento, dominancia en base a la defensa del recurso alimenticio, se observó una disminución de agresividad por parte del individuo dominante con respecto al subordinado durante la condición ( $a$; diferencia de medianas $=1, P<0.001$; Tabla 1). En las demás condiciones $(b, c$ y $d)$ del tercer experimento, la hembra dominante no presentó variación en la mediana = 6 (Tabla 1). Ambas hembras presentaron agresión hacia el macho; éste se limitó a evitar la agresión, presentando valores de sumisión ( 1 y 2 ) relacionados con la huida y el movimiento, respectivamente (datos no mostrados).

Dominancia interespecífica. La masa corporal promedio en gramos y la desviación estándar de 25 hembras adultas de cada especie, C. arenarius (11.17 \pm 2.33 ), C. ammophilus (11.8 \pm 3.26$), C$. spinatus (13.9 \pm 4.37$)$ y C. rudinoris (19.26 \pm 4.37$)$, demostró que C. siccus (10.6 \pm 1.44$)$ es la más pequeña de todas. La masa corporal en gramos de $C$. siccus no fue estadísticamente diferente con relación a la de $C$. arenarius y $C$. ammophilus (ANOVA de una vía; $F=1.511 ; g . l .=2,72 ; P=0.227$ ) y significativamente diferente con relación a la de $C$. spinatus y $C$. rudinoris ( $F=41.538 ;$ g. I. $=2,72 ; P$ $<0.001)$.

Chaetodipus siccus fue significativamente más agresiva que las otras cuatro especies $(P<0.001$; Tabla 1), incluso con especies de mayor masa corporal $(P<0.001)$. No hubo efecto de la masa corporal (tamaño) en el establecimiento de la jerarquía de dominancia, ni al momento de defender el recurso alimenticio entre $C$. siccus y las demás especies. En las cuatro combinaciones de especies (C. siccus - C. arenarius / C. ammophilus / C. spinatus / C. rudinoris), C. siccus, la más pequeña, resultó la especie dominante, mostrando conductas agresivas más frecuentemente que las demás, al defender el alimento $(P<0.001$; Tabla 1$)$. Después de los encuentros $(n=25)$ de cada 
Tabla 1. Prueba de los signos de Wilcoxon de los individuos dominante y subordinado de los experimentos 1,3 y 4 . Las condiciones del experimento de dominancia directa fueron: $a$ : entre dos hembras de la misma localidad; $b$ : entre dos hembras de la misma localidad con un proceso de familiarización; c: entre dos hembras de diferente localidad; y $d$ : entre dos hembras de diferente localidad con un proceso de familiarización. Las condiciones del experimento de dominancia con base en la defensa del recurso alimenticio fueron: $a$ : entre dos hembras en ayuno de $24 \mathrm{~h}$; $b$ : entre dos hembras alimentadas ad libitum; $c$ : entre la hembra dominante alimentada ad libitum y la subordinada en ayuno de $24 \mathrm{~h}$; $d$ : entre dos hembras alimentadas ad libitum con la presencia de un macho. Individuo dominante (D), individuo subordinado (s), estadístico de referencia $(Z)$, número de comportamientos observados durante cada condición (N) y significancia estadística ( $P$ ).

\begin{tabular}{|c|c|c|c|c|c|}
\hline \multirow{2}{*}{$\begin{array}{l}\text { Experimento } 1 \\
\text { Condición }\end{array}$} & \multicolumn{2}{|c|}{ Medianas } & \multicolumn{3}{|c|}{ Prueba de los signos de Wilcoxon } \\
\hline & $\mathrm{D}$ & s & $Z$ & $\mathrm{~N}$ & $P$ \\
\hline$a$ & 6 & 1 & 29.177 & 1195 & $<0.001$ \\
\hline$b$ & 6 & 2 & 20.849 & 952 & $<0.001$ \\
\hline$c$ & 6 & 1 & 27.868 & 1257 & $<0.001$ \\
\hline$d$ & 6 & 1 & 25.976 & 997 & $<0.001$ \\
\hline \multicolumn{6}{|l|}{ Experimento 3} \\
\hline$a$ & 3 & 2 & 23.263 & 781 & $<0.001$ \\
\hline$b$ & 6 & 1 & 21.828 & 824 & $<0.001$ \\
\hline$c$ & 6 & 2 & 18.053 & 873 & $<0.001$ \\
\hline$d$ & 6 & 1 & 17.079 & 473 & $<0.001$ \\
\hline \multicolumn{6}{|l|}{ Experimento 4} \\
\hline \multicolumn{6}{|c|}{ C. siccus-C.arenarius } \\
\hline$a$ & 3 & 2 & 9.702 & 425 & $<0.001$ \\
\hline$b$ & 3 & 2 & 7.283 & 285 & $<0.001$ \\
\hline$c$ & 3 & 2 & 11.470 & 400 & $<0.001$ \\
\hline \multicolumn{6}{|c|}{ C. siccus-C.ammophilus } \\
\hline$a$ & 4 & 2 & 12.820 & 562 & $<0.001$ \\
\hline$b$ & 3 & 2 & 13.530 & 540 & $<0.001$ \\
\hline c & 3 & 2 & 12.504 & 552 & $<0.001$ \\
\hline \multicolumn{6}{|c|}{ C. siccus-C. spinatus } \\
\hline$a$ & 3 & 2 & 13.249 & 473 & $<0.001$ \\
\hline$b$ & 3 & 2 & 11.644 & 357 & $<0.001$ \\
\hline$c$ & 3 & 2 & 12.817 & 498 & $<0.001$ \\
\hline \multicolumn{6}{|c|}{ C. siccus-C.rudinoris } \\
\hline$a$ & 3 & 2 & 7.362 & 750 & $<0.001$ \\
\hline$b$ & 3 & 2 & 6.481 & 647 & $<0.001$ \\
\hline$c$ & 3 & 2 & 8.809 & 868 & $<0.001$ \\
\hline
\end{tabular}

condición, C. siccus mostró un porcentaje mayor de dominancia, porcentaje basado en la suma de comportamientos de cada diada (Tabla 2).

\section{Discusión}

La red estadísticamente parsimoniosa de C. siccus, mostró una marcada estructura genética, con presencia considerable de haplotipos únicos. Por otro lado, no se pudo determinar la presencia de barreras físicas observables que limiten el flujo genético y, por consiguiente, la disminución en la panmixia. Se considera que la estructuración genética se produce cuando las subpoblaciones están al menos, parcialmente aisladas unas de otras, por ejemplo cuando el parentesco entre subpoblaciones decrece en función de la distancia geográfica entre individuos (Wright 1965; 1969; Cutrera et al. 2005; Dubuc-Messier et al. 2012). La ausencia de barreras físicas o geográficas visibles, aunado a la alta agresividad de las hembras de C. siccus, permite considerar que el flujo 
Tabla 2. Porcentaje de dominancia presentada por Chaetodipus siccus sobre las cuatro especies (con su respectivo porcentaje de masa corporal en gramos con respecto a C. siccus; C. arenarius, C. ammophilus, C. spinatus y C. rudinoris), durante los encuentros $(n=25)$ de las tres diferentes condiciones del experimento de dominancia con base en la defensa del recurso alimenticio. Condición $a$ (hembras en ayuno de 24 h), $b$ (ad libitum) y c (hembra dominante ad libitum / subordinada en ayuno de $24 \mathrm{~h}$ ).

\begin{tabular}{lcccc|}
\cline { 2 - 5 } & \multicolumn{4}{c}{ Dominancia de C. siccus sobre: } \\
\cline { 2 - 5 } & $\begin{array}{c}\text { C. arenarius } \\
(105 \%)\end{array}$ & $\begin{array}{c}\text { C. ammophilus } \\
(111 \%)\end{array}$ & $\begin{array}{c}\text { C. spinatus } \\
(131 \%)\end{array}$ & $\begin{array}{c}\text { C. rudinoris } \\
(181 \%)\end{array}$ \\
\cline { 2 - 5 } a) ambas ayuno & 84 & 80 & 72 & 56 \\
b) ambas ad libitum & 72 & 80 & 64 & 64 \\
c) dominante ad libitum & 75 & 80 & 88 & 80 \\
\hline
\end{tabular}

genético dentro de la población puede limitarse por interacciones etológicas (Storz 1999; Wang et al. 2011). Se ha determinado que la estructura también se relaciona estrechamente con procesos evolutivos fundamentales y con aspectos sociales del comportamiento como especiación, dispersión, estrategias de crianza y filopatría (Hamilton 1964; Wright 1965; Wilson 1975; Storz 1999; Ross 2001). Así mismo, se considera que los sistemas sociales y la estructura genética tienen una relación dinámica (Kappeler y van Schaik 2002), ya que las asociaciones entre individuos pueden aumentar la relación genética a nivel local y al mismo tiempo, diferenciar estructuralmente a la población (Wang et al. 2011).

Estructuras con inusual número de haplotipos en áreas reducidas de distribución, han sido previamente registradas para otros mamíferos. Es el caso del lémur ratón gris, Microcebus murinus en el que se detectaron 13 haplotipos mitocondriales (D-loop) en nueve hectáreas y a partir de 85 individuos (Wimmer et al. 2002). Se argumenta que este patrón es resultado de un carácter filopátrico de las hembras de la especie y flujo genético restringido entre áreas. En la rata Neotoma micropus se identificaron 42 haplotipos mitocondriales (D-loop) en $40 \mathrm{~km}^{2}$ a partir de 114 individuos (Méndez-Harclerode et al. 2005). Se argumenta que el patrón genético observado se debe al flujo limitado entre sitios separados entre dos y cinco kilómetros. Es interesante señalar que en los dos estudios anteriores se utilizó D-loop (0.32 sustituciones/sitio/1 millón de años; Sigurðardóttir et al. 2000) que tiene una tasa de mutación en promedio 1.8 veces más rápida que el Cytb y COI (13 y 42 haplotipos, respectivamente), que es un gen mitocondrial no codificante; mientras que los resultados para C. siccus corresponden a Cytb (0.176 sustituciones/sitio/1 millón de años en Rodentia; Nabholz et al. 2008) y COI (18\% más lento que Cytb; Lavinia et al. 2016), genes que sí codifican y tienen una tasa de mutación más lenta (53 y 15 haplotipos, respectivamente).

La explicación más plausible para la estructura genética obtenida para $C$. siccus es que las hembras presentan una organización filopátrica en la que a partir del establecimiento de jerarquías de dominancia, defienden el recurso alimento mediante alta agresividad. La existencia de varios linajes filomaternos restringidos geográficamente, sin barreras físicas que limiten su dispersión, propone el hecho de que las hembras no se dispersan, sino que se quedan dentro de un área geográfica muy pequeña. Esto apunta directamente a la presencia de filopatría en las hembras, la que obedece al conjunto de variables de naturaleza biológica, a las restricciones ecológicas presentes en el ambiente y a los beneficios que trae consigo la propia filopatría (Solomon 2003). Cuando la filopatría se observa en las poblaciones naturales, existe una agregación de hembras cercanamente emparentadas entre sí. El hecho de que existan este tipo de relaciones entre los individuos no supone el libre acceso a recursos o territorios, pero puede aumentar la sobrevivencia de la población en los ambientes áridos, donde la distribución de los recursos es extremadamente irregular. Es por esto que las jerarquías entre individuos resultan esenciales para el sano mantenimiento de las relaciones sociales (Rowell 1974; Kaufmann 1983).

Las conductas agonísticas son el medio por el cual un individuo mantiene su jerarquía ante otros, definiendo su acceso preferencial a los recursos (Newmark y Jenkins 2000; Kinahan y Pillay 
2008). En el caso de las hembras de C. siccus, su naturaleza extremadamente agresiva, así como un comportamiento evidentemente territorial, posiblemente sean los promotores de la segregación de linajes matrilineales. Esta segregación se comprobó con la identificación de 53 y 15 haplotipos de Cytb y COI respectivamente en $\sim 270$ km² $^{2}$, de los cuales 31 (55.3\%) para Cytb y 5 (35.3\%) para COI resultaron ser únicos, con una separación geográfica de menos de $2 \mathrm{~km}$ y sin barreras físicas observables que limiten la dispersión de los individuos. La media de las diferencias entre pares de haplotipos en Cytb $(\mu=4.23)$ y COI $(\mu=3.14)$ sugieren una considerable diferenciación entre haplotipos, lo que apoya una estructura al interior de la población de $C$. siccus.

Las diferencias sexuales de los individuos afectan directamente la estructura genética de las poblaciones (Chesser et al. 1993; Dixon 2011). Los machos que se dispersan serán los potenciales responsables del flujo genético, con lo que se mantiene la homogeneidad. Las hembras filopátricas serán las promotoras de discontinuidades genéticas en las poblaciones y de la retención de los lazos sociales entre hembras emparentadas, lo que resultará en un sistema matrilineal y matrifocal (Davis 1984; Dixon 2011). Estas discontinuidades se observan claramente en la distribución extremadamente localizada de los linajes matrilineales de C. siccus. Este fenómeno se ha observado entre hembras de la ardilla Spermophilus richardsonii (van Staaden et al. 1994, 1996) donde el carácter filopátrico se traduce en una distribución geográfica muy localizada y no al azar de los linajes matrilineales y los individuos estrechamente emparentados se encuentran espacialmente cerca unos de otros. Las hembras vecinas tienden a estar más relacionadas que lo esperado por el azar, no solo en toda la población, sino también al interior de cada linaje matrilineal.

Los extremos comportamientos agonísticos identificados entre hembras de C. siccus y discutidos más adelante sugieren la presencia de agresividad extrema, incluso entre hembras del mismo sitio de captura. Esto suscita la presencia de áreas de influencia bien delimitadas y dominadas a lo largo del tiempo por el mismo linaje matrilineal. Resultados similares se han observado para S. richardsonii (van Staaden et al. 1994, 1996) donde se identificó una mayor superposición de territorios de hembras estrechamente emparentadas. No se identificó cooperación o coparticipación de recursos, y cada hembra adulta conservó una zona núcleo y madrigueras natales separadas (Michener 1983; Innes et al. 2012). Esta clase de comportamientos resultan en una sociedad basada en pequeños grupos filopátricos que producen discontinuidades genéticas discretas (van Staaden et al. 1994), como los patrones matrilineales presentados por C. siccus.

La combinación de los resultados obtenidos en el presente trabajo con lo propuesto en los estudios anteriormente mencionados, permiten corroborar la presencia de estructura genética en linajes matrilineales, fenómeno que pueda tener su origen en el comportamiento territorial a partir de conductas extremadamente agresivas entre hembras de C. siccus. El conjunto de todos estos rasgos es una firma común de la presencia de filopatría en hembras.

Los análisis llevados al cabo permitieron identificar una relación dominante - subordinado, la cual permanece constante bajo diferentes condiciones. Es independiente de la localidad de captura y permanece constante incluso con un proceso de familiarización entre hembras. La coexistencia y el proceso de conocerse un individuo con otro durante su estadía en las cajas sociales, permitieron a cada ratón establecer familiaridad con su vecino. La familiaridad es un mecanismo que mitiga la agresión y promueve la tolerancia mutua entre individuos (Randall 1993; Shier y Randall 2007). En las hembras de C. siccus, la familiarización no parece haber provocado cambio en la dominancia o sumisión. Así mismo, los resultados están en contraposición a los obtenidos por (Shier y Randall 2007), quienes reportaron que después de un proceso de familiarización entre diadas, las conductas agonísticas disminuyeron, permitiendo una relación de tolerancia entre individuos. Esto posiblemente se deba a que el individuo subordinado reconoció su jerarquía frente al individuo dominante, relación que se reforzó durante el proceso de familiarización, mientras el dominante permitió ciertas conductas al individuo subordinado. La hembra dominante siempre impondrá su jerarquía sobre otra subordinada por medio de conductas agonísticas, pero que no necesariamente sean enfrentamientos, de manera que se pueda optimizar el gasto de energía (Silk 2007; Holekamp et al. 2012). 
Es importante señalar que el enfrentamiento en el que se determina la dominancia es muy breve (media de $\sim 1.5 \mathrm{~s}$ ) y después se mantiene. Esto implica que el proceso de dominancia no tiene un consumo alto de energía y que posterior al establecimiento de ésta, el resto de los comportamientos de la hembra subordinada tienden a ser evasivos. Los altos niveles de agresividad en hembras de $C$. siccus pueden estar relacionados a un comportamiento marcadamente territorial y el acaparamiento de los limitados recursos alimenticos presentes en cierta área, con lo que garantizan su éxito reproductivo.

La familiarización entre individuos de la misma localidad de captura parece haber tenido una ligera influencia en ambos individuos, en comparación con individuos que no siguieron el proceso de familiarización. La hembra subordinada mostró un intervalo más amplio de comportamientos, mientras que la dominante mantuvo su jerarquía. Para hembras de diferente localidad de colecta, con proceso de familiarización, el individuo subordinado presentó un intervalo constante de comportamientos, mientras que el dominante no disminuyó la agresión y mantuvo su jerarquía, en relación con las conductas presentadas por hembras sin familiarización. Estos datos, en conjunto, sugieren que la familiarización no afecta los niveles de agresividad presentados por los individuos dominantes.

La dominancia se mantuvo bajo las diferentes condiciones de defensa del recurso alimenticio. El individuo dominante se enfocó en obtener el recurso y la hembra subordinada circundó continuamente el área alrededor del alimento intentando hacerse con éste, mientras evitó la agresión de la dominante. La hembra subordinada mostró un intervalo mayor de comportamientos. Solamente en la condición en que ambas se enfrentaron en ayunas, se observaron variaciones. La dominante consumió tiempo alimentándose y guardando alimento en los abazones, presentando menos conductas agresivas. Por otro lado, la subordinada se pudo aproximar más al alimento, pero sin comprometer la jerarquía de la dominante.

Experimentos similares a los conducidos en este trabajo, se han empleado para estudiar comportamientos de dominancia y agresión intraespecíficos en heterómidos (e.g. Bleich y Price 1995; Shier y Randall 2007) y en múridos como Microtus ochrogaster (Harper y Batzli 1997). Los datos obtenidos en los estudios con C. siccus sugieren niveles de agresividad más altos que los previamente registrados para la rata canguro Dipodomys merriami (Randall 1989) y pocos o ningunos comportamientos agonísticos entre hembras de D. merriami (Newmark y Jenkins 2000). Sin embargo, no hay estudios que mencionen la presencia de jerarquías de dominancia entre los individuos pertenecientes a este género.

Cuando se incluye al macho en el experimento con C. siccus, ambas hembras exhibieron intensos comportamientos agonísticos hacia el macho. Estas observaciones refuerzan la idea de la naturaleza extremadamente agresiva de las hembras. La dominancia basada en altos niveles de agresividad, parece ser común entre hembras de Chaetodipus. En contraparte para D. merriami, los machos dominaron a las hembras (Newmark y Jenkins 2000).

La estructura genética presente en $C$. siccus es más compleja que para las otras especies del género Chaetodipus presentes en el sur de la península de Baja California (Álvarez-Castañeda y Rios 2011; Álvarez-Castañeda y Murphy 2014). Con este criterio se consideró que era necesario saber el grado de agresividad que puede presentar $C$. siccus con otras especies el género, considerando la masa corporal de las especies como unidad de medida de tamaño. Los resultados del estudio demostraron que $C$. siccus fue más agresiva que las demás especies, a pesar de que $C$. rudinoris prácticamente la duplica en peso y tamaño. Se ha detectado agresividad para la mayoría de los géneros (Dipodomys, Perognathus y Liomys) de heterómidos (Eisenberg 1963), es por ello que es de llamar la atención que la especie más pequeña sea la que domine a todas las demás. Por otra parte, se demuestra que $C$. siccus es una especie muy agresiva. Es por ello que cada hembra establece su área de influencia, la cual defiende y no permite el ingreso de otros individuos. Este hecho debe de influir de manera significativa la dispersión de individuos y por consiguiente, la limitación del flujo genético dentro del área de distribución. 
Esta serie de estudios muestran que las hembras de regiones desérticas con recursos alimenticios limitados, deben de tener conductas agresivas que permitan mantener su dominancia sobre otros individuos y especies. Estas agresiones son instantáneas, sin llegar a enfrentamientos que tengan un alto consumo de energía. La presencia de una serie de celdas o áreas de influencia, donde una hembra es dominante, tiene como resultado una limitada dispersión de las hembras, y posiblemente también de los machos. El presente estudio etológico demuestra una gran agresividad entre hembras, lo que se observa en el establecimiento de jerarquías de dominancia entre éstas. Tal condición se puede interpretar como el medio que propicia una marcada territorialidad femenina, en la que no se permite el libre tránsito de individuos. Las limitantes de la dispersión pueden ser un factor importante en la reducción de la panmixia poblacional de C. siccus, que, a su vez, puede ser reflejada en la presencia de haplotipos matrilineales aislados y específicos a ciertas localidades geográficas.

\section{Agradecimientos}

El autor agradece a L. Nájera C., I. Gutiérrez R., M. de la Paz C., A. Rodríguez, A. Campos, J. Pérez, C. Segura e I. Camargo por su gran ayuda en el campo y durante los experimentos. Al laboratorio de Mastozoología y a G. Gallegos S. del Nodo Cibnor Código de Barras. AI CIBNOR por las facilidades e instalaciones prestadas, a CONACyT por la beca de doctorado otorgada y por aportar los fondos para el proyecto 084C.

\section{Literatura citada}

Álvarez-Castañeda, S. T., y E. Rıos. 2011. Revision of Chaetodipus arenarius (Rodentia: Heteromyidae). Zoological Journal of the Linnean Society 161:213-228.

Álvarez-Castañeda, S. T., y R. W. Murphy. 2014. The Endemic Insular and Peninsular Species Chaetodipus spinatus (Mammalia, Heteromyidae) Breaks Patterns for Baja California. PLoS ONE 9:e116146. doi:10.1371/journal.pone.0116146

Avise, J. C. 2000. Phylogeography. The History and Formation of Species. Harvard University Press. Cambridge, EE. UU.

Bleich, V. C., y M. V. Price. 1995. Aggressive behavior of Dipodomys stephensi, and Dipodomys agilis, a sympatric congener. Journal of Mammalogy 76:646-651.

Blumstein, D. T., y K. B. Armitage. 1999. Cooperative breeding in marmots. Oikos 84: 369-382.

Brown, J. H., Y B. A. Harney. 1993. Population and community ecology of heteromyid rodents in temperate habitats. Pp. 618-651 en Biology of the Heteromyidae (Genoways, H. H., y J. H. Brown, eds.). Special publications No. 10, American Society of Mammalogists. Lawrence, EE. UU.

Chesser, R. K. 1991. Gene diversity and female philopatry. Genetics 127:437-447.

Chesser, R. K., O. E. Rhodes JR., D. W. Sugg, y A. Schnabel. 1993. Effective sizes for subdivided populations. Genetics 135:1221-1232.

Clement, M., D. Posada, y K. A. CRandall. 2000. TCS: a computer program to estimate gene genealogies. Molecular Ecology 9:1657-1660.

Clutton-Brock, T. H. 1989. Mammalian mating systems. Proceedings of the Royal Society of London. Series B, Biological Sciences 236:339-372.

Clutton-Brock, T. H., y D. LuKas. 2012. The evolution of social philopatry and dispersal in female mammals. Molecular Ecology 21:472-492.

Cooper, L. D., y J. A. Randall. 2007. Seasonal changes in the home ranges of the giant kangaroo rat (Dipodomys ingens): a study of flexible social structure. Journal of Mammalogy 88:1000-1008.

Cutrera, A. P., E. A. Lacey, y C. Busch. 2005. Genetic structure in solitary rodent (Ctenomys talarum): implications for kinship and dispersal. Molecular Ecology 14:2511-2523.

Davis, L. S. 1984. Behavioral interactions of Richardson's ground squirrels: asymmetries based on kinship. Pp. 459-460 en Biology of ground-dwelling squirrels: annual cycles, behavioral ecology, and sociality (Murie, J. O., y G. R. Michener, eds.). University of Nebraska Press. Lincoln, EE. UU. 
Dixon, M. D. 2011. Population genetic structure and natal philopatry in the widespread North American bat Myotis lucifugus. Journal of Mammalogy 92:1343-1351.

Doebeli, M., y U. Dieckmann. 2003. Speciation along environmental gradients. Nature 421:259-264.

Dubuc-Messier, G., D. Garant, P. Bergeron, y D. Réale. 2012. Environmental conditions affect spatial genetic structures and dispersal patterns in a solitary rodent. Molecular Ecology 21:5363-5373.

EISENBERG, J. F. 1963. The behavior of heteromyid rodents. University of California Publications in Zoology 69:1-100.

Excoffier, L., G. Laval, y S. Schneider. 2005. Arlequin ver. 3.0: An integrated software package for population genetics data analysis. Evolutionary Bioinformatics Online 1:47-50.

Genoways, H. H., y J. H. Brown. 1993. Biology of the heteromyidae. American Society of Mammalogists. Shippensburg, EE. UU.

GreEnWOod, P. J. 1980. Mating systems, philopatry and dispersal in birds and mammals. Animal Behaviour 28:1140-1162.

Hamilton, W. D. 1964. The genetical evolution of social behavior Il. Journal of Theoretical Biology 7:17-52.

HARPER, S. J., Y G. O. BATZIL. 1997. Monitoring use of runways by voles with passive integrated transponders. Journal of Mammalogy 77:364-369.

Hedrick, P. 2001. Conservation genetics: where are we now? Trends in Ecology and Evolution. 16:629-636.

Holekamp, K.E., J. E. Smith, C. C. Strelioff, R. C. Van Horn, y H. E. Watts. 2012. Society, demography and genetic structure in the spotted hyena. Molecular Ecology 21:613-632.

Innes, R. J., M. B. McEachern, D. H. Van Vuren, J. M. Eadie, D. A. Kelt, y M. L. Johnson. 2012. Genetic relatedness and spatial associations of dusky-footed woodrats (Neotoma fuscipes). Journal of Mammalogy 93:439-446.

Johannesen, E., J. Brudevoll, M. Jenstad, L. Korslund, y S. Kristoffersen. 2002. Behavioural dominance of grey-sided voles over bank voles in dyadic encounters. Annales Zoologici Fennici 39:43-47.

Jones, W. T. 1993. The social systems of heteromyid rodents. Pp. 575-595 en Biology of the Heteromyidae (Genoways, H. H., y J. H. Brown, eds.). Special Publications No. 10. The American Society of Mammalogists. Shippensburg, EE. UU.

Kappeler, P. M., B. Wimmer, D. Zinner, y D. Tautz. 2002. The hidden matrilineal structure of a solitary lemur: implications for primate social evolution. Proceedings of the Royal Society of London. Series B, Biological Sciences 269:1755-1763.

Kappeler, P. M., y C. P. van Schaik. 2002. Evolution of primate social systems. International Journal of Primatology 23:707-740.

Kaufmann, J. H. 1983. On the definitions and functions of dominance and territoriality. Biological Reviews 58:1-20.

Kinahan A. A., y N. Pillay. 2008. Dominance status influences female reproductive strategy in a territorial african rodent Rhabdomys pumilio. Behavioral Ecology and Sociobiology 62:579-587.

LACEY, E. A. 2000. Spatial and social systems of subterranean rodents. Pp. 255-296 en Life underground: the biology of subterranean rodents (Lacey, E. A., J. L. Patton, y G. N. Cameron, eds.). University of Chicago Press. Chicago, EE. UU.

Lavinia, P. D., K. C. R. Kerr, P. L. Tubaro, P. D. N. Hebert, y D. A. LiJtmaer. 2016. Calibrating the molecular clock beyond cytochrome $b$ : assessing the evolutionary rate of $\mathrm{COI}$ in birds. Journal of Avian Biology 47:84-91.

MacArthuR, R. H. 1972. Geographical ecology: patterns in the distribution of species. Harper y Row. New York, EE. UU.

McGuire, B., L. L. Getz, J. E. Hofmann, T. Pizzuto, y B. Frase. 1993. Natal dispersal and philopatry in prairie voles (Microtus ochrogaster) in relation to population density, season, and natal social environment. Behavioral Ecology and Sociobiology 32:293-302.

Méndez-Harclerode, F. M., J. D. Hanson, C. F. Fulhorst, M. L. Milazzo, D. C. Ruthven III, y R. D. Bradley. 2005. Genetic diversity within the southern plains woodrat (Neotoma micropus) in southern Texas. Journal of Mammalogy 86:180-190.

Merriam, C. H. 1894. Descriptions of four new pocket mice from Lower California, collected by Walter E. Bryan. Proceedings of the California Academy of Sciences, Series 2 4:457-462. 
Meshriy, M. G, J. A. Randall, y L. Randall. 2011. Kinship associations of a solitary rodent, Dipodomys ingens, at fluctuating population densities. Animal Behaviour 82:643-650.

Michener, G. R. 1983. Kin identification, matriarchies and the evolution of sociality in ground-dwelling sciurids. Pp. 528-572 en Advances in the Study of Mammalian Behavior, Vol. 7 (Eisenberg, J. F., y D. G. Kleiman, eds.). American Society of Mammalogists. Lawrence, EE. UU.

Moyninan, M. 1998. The social regulation of competition and aggression in animals. Smithsonian Institution Press. Washington, EE. UU.

Nabholz, B., S. Glémin, y N. Galtier. 2008. Strong variations of mitocondrial mutation rate across mammals-the longevity hypothesis. Molecular Biology and Evolution 25:120-130.

Neiswenter, S. A., y B. R. Riddle. 2010. Diversification of the Perognathus flavus species group in arid grasslands of western North America. Journal of Mammalogy 91:348-362.

Newmark, J. E., y S. H. Jenkins. 2000. Sex differences in agonistic behavior of Merriam's kangaroo rats (Dipodomys merriami). The American Midland Naturalist 143:377-388.

Nowak, R. M. 1999. Walker's mammals of the world, 6th ed. Johns Hopkins University Press. Baltimore, EE. UU.

Oleinichenko, V. Y. 2000. Behavior of the shrews Sorex volnuchini and S. raddei. Zoologichesky Zhurnal 79:939-953.

Osgood, W. H. 1907. Four new pocket mice. Proceedings of the Biological Society of Washington 20:19-22.

Patton, J. L., y S. T. Álvarez-Castañeda. 1999. Family Heteromyidae. Pp. 351-443 en Mamíferos del Noroeste de México (Álvarez-Castañeda, S. T., y J. L. Patton, eds.). Centro de Investigaciones Biológicas del Noroeste. La Paz, México.

PerRi, M., y J. A. Randall. 1999. Behavioral mechanisms of coexistence in sympatric species of desert rodents, Dipodomys ordii and D. merriami. Journal of Mammalogy 80:1297-1310.

RandalL, J. A. 1984a. Mating strategies of a nocturnal desert rodent (Dipodomys spectabilis). Behavioral Ecology and Sociobiology 28:215-220.

Randall, J. A. 1984b. Territorial defense and advertisement by footdrumming in Bannertail kangaroo rats (Dipodomys spectabilis) at high and low population densities. Behavioral Ecology and Sociobiology 16:11-20.

RANDALL, J. A. 1989. Neighbor recognition in a solitary desert rodent (Dipodomys merriami). Ethology 81:123-133.

Randall, J. A. 1993. Behavioural adaptations of desert rodents (Heteromyidae). Animal Behaviour 45:263-287.

Rıos E., y S. T. Álvarez-Castañeda. 2013. Nomenclatural change of Chaetodipus dalquesti. Western North America Naturalist 73:399-400.

Ross, K. G. 2001. Molecular ecology of social behaviour: analyses of breeding systems and genetic structure. Molecular Ecology 10:265-284.

Rотн, E. L. 1976. A new species of pocket mouse (Perognathus: Heteromyidae) from the Cape Region of Baja California Sur, Mexico. Journal of Mammalogy 57:562-566.

RoweLL, T. E. 1974. Concept of social dominance. Behavioral Biology 11:131-154.

Rychlik, L., Y R. Zwolak. 2006. Interespecific aggression and behavioural dominance among four sympatric species of shrews. Canadian Journal of Zoology 84:434-448.

Shier, D. M., y J. A. Randall. 2007. Use of different signaling modalities to communicate status by dominant and subordinate Heermann's kangaroo rats (Dipodomys heermanni). Behavioral Ecology and Sociobiology 61:1023-1032.

Sigureardóttir, S., A. Helgason, J. R, Gulcher, K. Stefansson, y P. Donnelly. 2000. The mutation rate in the human mtDNA control region. American Journal of Human Genetics 66:1599-1609.

Sikes, R. S., W. L., Gannon, and the Animal Care and Use Committee of the American Society of Mammalogists. 2011. Guidelines of the American Society of Mammalogists for the Use of Wild Mammals in Research. Journal of Mammalogy 92:235-253.

SiLk, J. B. 2007. The adaptive value of sociality in mammalian groups. Philosophical transactions of the Royal Society of London. Series B, Biological sciences 362:539-559. 
Solomon, N. G. 2003. A reexamination of factors influencing philopatry in rodents. Journal of Mammalogy 84:1182-1197.

Solomon, N. G., y L. L. Getz. 1997. Examination of alternative hypotheses for cooperative breeding in rodents. Pp. 199-230 en Cooperative breeding in mammals (Solomon, N. G., and J. A. French, eds.). Cambridge University Press. New York, EE. UU.

van Staaden, M. J., R. K. Chesser, y G. R. Michener. 1994. Genetic correlations and matrilineal structure in a population of Spermophilus richardsonii. Journal of Mammalogy 75:573-582.

van Staaden, M. J., G. R. Michener, y R. K. Chesser. 1996. Spatial analysis of microgeographic genetic structure in Richardson's ground squirrels. Canadian Journal of Zoology 74:1187-1195.

Storz, J. F. 1999. Genetic consequences of mammalian social structure. Journal of Mammalogy 80:553-569.

TAлima, F. 1993. Measurement of DNA polymorphism. Pp. 37-59 en Mechanisms of molecular Evolution. Introduction to molecular paleopopulation biology (Takahata, N., y A. G. Clark, eds.). Japanese Scientific Societies Press, Sinauer Associates, Inc. Tokyo, Japón.

Templeton, A.R., K. A. Crandall, y C. F. Sing. 1992. A cladistic analysis of phenotypic associations with haplotypes inferred from restriction endonuclease mapping and DNA sequence data. III. Cladogram estimation. Genetics 132:619-633.

Vander Wall, S. B. 1990. Food Hoarding in Animals. University of Chicago Press. Chicago, EE. UU.

Vaughan, T. A., J. A. Ryan, y N. J. Czaplewski. 2000. Mammalogy, fourth ed. Harcourt College Publishers. EE. UU.

Vázquez, J., y S. T. Álvarez-Castañeda. 2011. Spatial relationships between burrows of an insular population of Dipodomys merriami. Mammalian Biology 76:577-582.

WANG, Y., W. Liu, G. M. WANG, W. Zhong, y X. WAN. 2011. Genetic Consequences of Group Living in Mongolian Gerbils. The Journal of Heredity 102:554-561.

WASER, P. M., Y W. T. Jones. 1983. Natal philopatry among solitary mammals. The Quarterly Review of Biology 58:355-390.

WeIss, C. H. 2007. Statistica v8, StatSoft, Inc. AStA Advances in Statistical Analysis 91:339-341.

WILcoxon, F. 1945. Individual comparisons by ranking methods. Biometrics Bulletin 1:80-83.

WILson, E. O. 1975. Sociobiology: The new synthesis. Belknap. Cambridge, EE. UU.

Wimmer, B., D. Tautz, y P. M. Kappeler. 2002. The genetic population structure of the gray mouse lemur (Microcebus murinus), a basal primate from Madagascar. Behavioral Ecology and Sociobiology 52:166-175.

Winters, J. B., Y P. M. WASER. 2003. Gene dispersal and outbreeding in philopatric mammal. Molecular Ecology 12:2251-2259.

WRIGHT, S. 1965. The interpretation of population structure by F-Statistics with special regard to systems of mating. Evolution 19:395-420.

WrIGHT, S. 1969. Evolution and the genetics of populations. The theory of gene frequencies. The University of Chicago Press. Chicago, EE. UU.

YoerG, S. I. 1999. Solitary is not asocial: effects of social contact in kangaroo rats (Heteromyidae: Dipodomys heermanni). Ethology 105:317-333.

YoerG, S. I., Y D. M. Shier. 2000. Captive breeding and anti-predator behavior of the Heermann's kangaroo rat (Dipodomys heermanni). Pp 1-56 en Final Report. California Department of Fish and Game. Sacramento, EE. UU.

Submitted: March 27, 2016

Reviewed: May 1, 2016

Accepted: May 4, 2016

Associated editor: Consuelo Lorenzo 
Anexo 1A. Localidades de colecta visitadas $(n=34)$ y número de haplotipo (Cytb y COI) de Chaetodipus siccus registrado por localidad.

\begin{tabular}{|c|c|c|c|}
\hline $\begin{array}{c}\text { Número } \\
\text { de } \\
\text { localidad }\end{array}$ & Haplotipo Cytb & $\begin{array}{c}\text { Haplotipo } \\
\text { COI }\end{array}$ & Localidad; coordenadas \\
\hline
\end{tabular}

\begin{tabular}{|c|c|c|c|}
\hline 1 & $1,2,3,4$ & $1,2,16$ & Isla Cerralvo; 24.1555, -109.8692. \\
\hline 2 & 5,6 & 3,4 & 8.1 km N, 6.3 km E Los Planes; 24.0377, -109.8729. \\
\hline 3 & $7,8$. & 1,5 . & 7 km N Los Planes; 24.0261, -109.9340. \\
\hline 4 & 9,10 & 9,10 & 6 km N, 8 km W Los Planes; 24.0226, -110.0146. \\
\hline 5 & $6,8,9,11,12,13,14$ & $1,4,10,11,12$ & 6 km N, 2 km E Los Planes; 24.0207, -109.9175. \\
\hline 6 & $1,6,7,8,9,15,16$ & $1,4,5$ & 5.3 km N Los Planes; 24.0152, -109.9334. \\
\hline 7 & 9,18 & 1. & 3 km N, 2.6 km W Los Planes; 23.9959, -109.9616. \\
\hline 8 & $9,17,18,19,20$. & 1,4 . & Ensenada de Muertos; 23.9992, -109.8269. \\
\hline 9 & 18,21 & 1,11 & 0.5 km S, 6.1 km W Los Planes; 23.9625, -109.9978. \\
\hline 10 & $22,23$. & 1. & 1.3 km S, 0.8 km E Los Planes; 23.9549, -109.9278. \\
\hline 11 & 24. & 4. & 2.5 km S Los Planes; 23.9446, -109.9363. \\
\hline 12 & $1,23,25$ & 1,8 . & 3 km S, 7 km W Los Planes; 23.9440, -110.0060. \\
\hline 13 & $9,26,27$ & 1. & 3.1 km S, 4 km W Los Planes; 23.9371, -109.8971. \\
\hline 14 & $6,9,18,28$ & $1,4,14$ & 3.7 km S, 1 km W Los Planes; 23.9334, -109.9480. \\
\hline 15 & $1,9,18,29,30,31$ & $1,4,10,15$ & 4.3 km S Los Planes; 23.9283, -109.9358. \\
\hline 16 & $18,25,32,33,34,35$. & $1,4,6,7,8,13$ & 4.5 km S, 1.9 km E Los Planes; 23.9254, -109.9170. \\
\hline 17 & $1,9,18,36,37$ & 1,4 & 5 km S, 1.6 km W Los Planes; 23.9232, -109.9535. \\
\hline 18 & $19,23,38$ & $1,4$. & 5.7 km S, 8 km W Los Planes; 23.9155, -110.0164. \\
\hline 19 & $9,17,19,39,40,41$ & $1,4,17$ & 6 km S, 2.8 km W Los Planes; 23.9130, -109.9073. \\
\hline 20 & 17,18 & 1,4 & 6 km S, 1 km E Los Planes; 23.9138, -109.9307. \\
\hline 21 & $20,42,43$. & 1. & 7 km S, 8 km W Los Planes; 23.9044, -110.016. \\
\hline 22 & 1,49 & 1. & 7.4 km S, 8.6 km W Los Planes; 23.8990, -110.0218. \\
\hline 23 & $\begin{array}{l}18,31,44,45,46,47 \\
48 .\end{array}$ & $1,3,4,10$ & 7.5 km S, 7.6 km W Los Planes; 23.9005, -110.0121. \\
\hline 24 & $5,9,14,23,37$ & $1,3,4,12$ & 8.7 km S, 8 km W Los Planes; 23.8893, -110.0183. \\
\hline 25 & 39. & 1. & 9.1 km S, 2.9 km W Los Planes; 23.8850, -109.9073. \\
\hline 26 & $9,18,19,23,35,39$ & 1,4 . & 9.2 km S, 3.1 km W Los Planes; 23.8828, -109.9663. \\
\hline 27 & $9,18,39,50$ & 1. & 10.3 km S, 7.4 km W Los Planes; 23.8742, -110.0091. \\
\hline 28 & 9,33 & 1,7 & 10.4 km S, 6 km W Los Planes; 23.8728, -109.9914. \\
\hline 29 & 38. & 1. & 10.4 km S, 5.5 km W Los Planes; 23.8708, -109.9663. \\
\hline 30 & $9,18,36$ & 1,4 . & 10.6 km S, 3 km W Los Planes; 23.872916, -109.9906. \\
\hline 31 & $18,52,53$ & $1,7$. & 11 km S, 8 km W Los Planes; 23.8712, -110.013611. \\
\hline 32 & $24,35,51,54$ & 4. & 11 km S, 3.7 km W Los Planes; 23.8703, -109.9711. \\
\hline 33 & 55. & 4. & 11.5 km S, 8.7 km W Los Planes; 23.8635, -110.0209. \\
\hline 34 & $1,18,56$ & 1,4 & 11.8 km S, 0.6 km E Los Planes; 23.8598, -109.9300. \\
\hline
\end{tabular}


Anexo 1B. Haplotipos de Citocromo $b(C y t b)$, número de acceso y localidades $(n=34)$ de referencia de los especímenes de Chaetodipus siccus. Las localidades y especímenes se presentan como (latitud, -longitud; número de catálogo CIB).

Haplotipo 1 (GQ241440): Isla Cerralvo (24.1611, -109.8638; 230, 235. 24.1555, -109.8692; 16069. 24.1527, -109.8697; 5594); 5.3 km N Los Planes (24.0152, -109.9334; 19329); 3 km S, 7 km W Los Planes (23.9440, -1 10.0060; 19026); 4.3 km S Los Planes (23.9283, -109.9358; 18651, 18659); 5 km S, 1.6 km W Los Planes (23.9232, -109.9535; 18662); 7.4 km S, 8.6 km W Los Planes (23.8990, -110.0218; 19071, 19073); 11.8 km S, 0.6 km E Los Planes (23.8598, -109.9300; 19513). Haplotipo 2 (KT321873): Isla Cerralvo (24.1555, -109. 8692; 16065, 16070). Haplotipo 3 (KT321874): Isla Cerralvo (24.1555, -109. 8692; 16066). Haplotipo 4 (KT321875): Isla Cerralvo (24.1555, -109.8692; 16067, 16068). Haplotipo 5 (KT321876): 8.1 km N, 6.3 km E Los Planes (24.0377, -109.8729; 19304); 8.7 km S, 8 km W Los Planes (23.8893, -110.0183; 19461). Haplotipo 6 (KT321877): 8.1 km N, 6.3 km E Los Planes (24.0377, -109.8729; 19305); 6 km N, 2 km E Los Planes (24.0207, -109.9175; 19314); 5.3 km N Los Planes (24.0152, -109.9334; 19323); 3.7 km S, 1 km W Los Planes (23.9334, -109.9480; 19259). Haplotipo 7 (KT321878): 7 km N Los Planes (24.0261, -109.9340; 19306); 5.3 km N Los Planes (24.0152, -109.9334; 19321). Haplotipo 8 (KT321879): 7 km N Los Planes (24.0261, -109.9340; 19307); 6 km N, 2 km E Los Planes (24.0207, -109.9175; 19308, 19310, 19313); 5.3 km N Los Planes (24.0152, -109.9334; 19325). Haplotipo 9 (KT321880): 6 km N, 8 km W Los Planes (24.0226, -110.0146; 18998, 19000); 6 km N, 2 km E Los Planes (24.0207, -109.9175; 19315); 5.3 km N Los Planes (24.0152, -109.9334; 19327); Ensenada de Muertos (23.9992, -109.8269; 5600); 3 km N, 2.6 km W Los Planes (23.9959, -109.9616; 19014); 3.1 km S, 4 km W Los Planes (23.9371, -109.8971; 19337); 3.7 km S, 1 km W Los Planes (23.9334, -109.9480; 19339); 4.3 km S Los Planes (23.9283, -109.9358; 15423; 18655, 18656, 18657); 5 km S, 1.6 km W Los Planes (23.9232, -109.9535; 19388); 6 km S, 2.8 km W Los Planes (23.9130, -109.9073; 19441, 19445); 8.7 km S, 8 km W Los Planes (23.8893, -110.0183; 19466); 9.2 km S, 3.1 km W Los Planes (23.8828, -109.9663; 19477); $10.3 \mathrm{~km} \mathrm{S,}$ 7.4 km W Los Planes (23.8742, -1 10.0091; 19492); 10.6 km S, 3 km W Los Planes (23.8729, -109.9906; 19104); 10.4 km S, 6 km W Los Planes (23.8728, -109.9914; 19496, 19497). Haplotipo 10 (KT321881): 6 km N, 8 km W Los Planes (24.0226, -110.0146; 18999). Haplotipo 11 (KT321882): 6 km N, 2 km E Los Planes (24.0207, -109.9175; 19309, 19312). Haplotipo 12 (KT321883): 6 km N, 2 km E Los Planes (24.0207, -109.9175; 19311). Haplotipo 13 (KT321884): 6 km N, 2 km E Los Planes (24.0207, -109.9175; 19316). Haplotipo 14 (KT321885): 6 km N, 2 km E Los Planes (24.0207, -109.9175; 19317); 8.7 km S, 8 km W Los Planes (23.8893, -110.0183; 19463). Haplotipo 15 (KT321886): 5.3 km N Los Planes (24.0152, -109.9334; 19320). Haplotipo 16 (KT321887): 5.3 km N Los Planes (24.0152, -109.9334; 19322). Haplotipo 17 (KT321888): Ensenada de Muertos (23.9992, -109.8269; 5601, 5603, 5604); 6 km S, 1 km E Los Planes (23.9138, -109.9307; 17405); 6 km S, 2.8 km W Los Planes (23.9130, -109.9073; 19447). Haplotipo 18 (KT321889): Ensenada de Muertos (23.9992, -109.8269; 5602, 5614); 3 km N, 2.6 km W Los Planes (23.9959, -109.9616; 19013); 0.5 km S, 6.1 km W Los Planes (23.9625, -109.9978; 19037); 3.7 km S, 1 km W Los Planes (23.9334, -109.9480; 19342); 4.3 km S Los Planes (23.9283, -109.9358; 15421, 18654, 18658, 18661); 4.5 km S, 1.9 km E Los Planes (23.9254, -109.9170; 18669); 5 km S, 1.6 km W Los Planes (23.9232, -109.9535; 19387); 6 km S, 1 km E Los Planes (23.9138, -109.9307; 17404); 7.5 km S, 7.6 km W Los Planes (23.9005, -110.0121; 19451, 19452); 9.2 km S, 3.1 km W Los Planes (23.8828, -109.9663; 19470, 19476); 10.3 km S, 7.4 km W Los Planes (23.8742,-110.0091; 19489, 19490, 19494); 10.6 km S, 3 km W Los Planes (23.8729, -109.9906; 19105); 11 km S, 8 km W Los Planes (23.8712, -110.0136; 19127); 11.8 km S, 0.6 km E Los Planes (23.8598, -109.9300; 19511). Haplotipo 19 (KT321890): Ensenada de Muertos (23.9992, -109.8269; 5611); 5.7 km S, 8 km W Los Planes (23.9155, -110.0164; 19051); 6 km S, 2.8 km W Los Planes (23.9130, -109.9073; 19439); 9.2 km S, 3.1 km W Los Planes (23.8828, -109.9663; 19479). Haplotipo 20 (KT321891): Ensenada de Muertos (23.999222, -109.8269; 5613); 7 km S, 8 km W Los Planes 
(23.9044, -110.016; 19066). Haplotipo 21 (KT321892): 0.5 km S, 6.1 km W Los Planes (23.9625, -109.9978; 19035, 19036). Haplotipo 22 (KT321893): 1.3 km S, 0.8 km E Los Planes (23.9549, -109.9278; 19331). Haplotipo 23 (KT321894): 1.3 km S, 0.8 km E Los Planes (23.9549, -109.9278; 19332); 3 km S, 7 km W Los Planes (23.9440, -1 10.0060; 19025); 5.7 km S, 8 km W Los Planes (23.9155, -110.0164; 19050); 8.7 km S, 8 km W Los Planes (23.8893, -110.0183; 19464, 19467); 9.2 km S, 3.1 km W Los Planes (23.8828, -109.9663; 19474). Haplotipo 24 (KT321895): 2.5 km S Los Planes (23.9446, -109.9363; 19334); 11 km S, 3.7 km W Los Planes (23.8703, -109.9711; 19117). Haplotipo 25 (KT321896): 3 km S, 7 km W Los Planes (23.9440, -110.0060; 19027); 4.5 km S, 1.9 km E Los Planes (23.9254, -109.9170; 18668). Haplotipo 26 (KT321897): 3.1 km S, 4 km W Los Planes (23.9371, -109.8971; 19335). Haplotipo 27 (KT321898): 3.1 km S, 4 km W Los Planes (23.9371, -109.8971; 19336). Haplotipo 28 (KT321899): 3.7 km S, 1 km W Los Planes (23.9334, -109.9480; 19343). Haplotipo 29 (KT321900): 4.3 km S Los Planes (23.9283, -109.9358; 15422, 18660). Haplotipo 30 (KT321901): 4.3 km S Los Planes (23.9283, -109.9358; 18650, 18652). Haplotipo 31 (KT321902): 4.3 km S Los Planes (23.9283, -109.9358; 18653); 7.5 km S, 7.6 km W Los Planes (23.9005, -110.0121; 19459). Haplotipo 32 (KT321903): 4.5 km S, 1.9 km E Los Planes (23.9254, -109.9170; 18664). Haplotipo 33 (KT321904): 4.5 km S, 1.9 km E Los Planes (23.9254, -109.9170; 18665); 10.4 km S, 6 km W Los Planes $(23.8728,-109.9914 ; 19495)$. Haplotipo 34 (KT321905): 4.5 km S, 1.9 km E Los Planes (23.9254, -109.9170; 18666). Haplotipo 35 (KT321906): 4.5 km S, 1.9 km E Los Planes (23.9254, -109.9170; 18667); 9.2 km S, 3.1 km W Los Planes (23.8828, -109.9663; 19471); 11 km S, 3.7 km W Los Planes (23.8703, -109.9711; 19116). Haplotipo 36 (KT321907): 5 km S, 1.6 km W Los Planes (23.9232, -109.9530; 18663); 10.6 km S, 3 km W Los Planes (23.8729, -109.9906; 19106). Haplotipo 37 (KT321908): 5 km S, 1.6 km W Los Planes (23.9232, -109.9530; 19386); 8.7 km S, 8 km W Los Planes (23.8893, -110.0183; 19465). Haplotipo 38 (KT321909): 5.7 km S, 8 km W Los Planes (23.9155, -110.0164; 19049); 10.4 km S, 5.5 km W Los Planes $(23.8708,-109.9663 ; 19085,19086)$. Haplotipo 39 (KT321910): 6 km S, 2.8 km W Los Planes (23.9130, -109.9073; 19436); 9.1 km S, 2.9 km W Los Planes (23.8850, -109.9073; 19468, 19469); 9.2 km S, 3.1 km W Los Planes (23.8828, -109.9663; 19478); 10.3 km S, 7.4 km W Los Planes (23.8742, -110.0091; 19486). Haplotipo 40 (KT321911): 6 km S, 2.8 km W Los Planes (23.9130, -109.9073; 19440). Haplotipo 41 (KT321912): 6 km S, 2.8 km W Los Planes (23.9130, -109.9073; 19442). Haplotipo 42 (KT321913): 7 km S, 8 km W Los Planes (23.9044, -110.016; 19067). Haplotipo 43 (KT321914): 7 km S, 8 km W Los Planes (23.9044, -110.016; 19068). Haplotipo 44 (KT321915): 7.5 km S, 7.6 km W Los Planes (23.9005, -110.0121; 19453). Haplotipo 45 (KT321916): 7.5 km S, 7.6 km W Los Planes (23.9005, -110.0121; 19454). Haplotipo 46 (KT321917): 7.5 km S, 7.6 km W Los Planes (23.9005, -110.0121; 19455). Haplotipo 47 (KT321918): 7.5 km S, 7.6 km W Los Planes (23.9005, -110.0121; 19456). Haplotipo 48 (KT321919): 7.5 km S, 7.6 km W Los Planes (23.9005, -110.0121; 194609). Haplotipo 49 (KT321920): 7.4 km S, 8.6 km W Los Planes (23.8990, -110.0218; 19072). Haplotipo 50 (KT321921): $10.3 \mathrm{~km} \mathrm{S,} 7.4 \mathrm{~km} \mathrm{~W}$ Los Planes (23.8742, -110.0091; 19491). Haplotipo 51 (KT321922): 11 km S, 3.7 km W Los Planes (23.8703, -109.9711; 19508). Haplotipo 52 (KT321923): 11 km S, 8 km W Los Planes (23.8712, -110.0136; 19126). Haplotipo 53 (KT321924): 11 km S, 8 km W Los Planes (23.8712, -110.0136; 19128). Haplotipo 54 (KT321925): 11 km S, 3.7 km W Los Planes (23.8703, -109.9711; 19118). Haplotipo 55 (KT321926): 11.5 km S, 8.7 km W Los Planes (23.8635, -110.0209; 17406). Haplotipo 56 (KT321927): 11.8 km S, 0.6 km E Los Planes (23.8598, -109.9300; 19512). 
Anexo 1C. Haplotipos de Citocromo c oxidasa subunidad I (COI), número de acceso de y localidades $(n=34)$ de referencia de los especímenes de Chaetodipus siccus. Las localidades y especímenes se presentan como (latitud, -longitud; número de catálogo CIB).

Haplotipo 1 (KT321928): Isla Cerralvo (24.1555, -109.8692; 5594, 16065, 16066, 16069, 16070); 7 km N Los Planes (24.0261, -109.9340; 19307); 6 km N, 8 km W Los Planes (24.0226, -110.0146; 18998, 19000); 6 km N, 2 km E Los Planes (24.0207, -109.9175; 19308, 19310; 19315); 5.3 km N Los Planes (24.0152, -109.9334; 19325, 19327, 19329); 3 km N, 2.6 km W Los Planes (23.9959, -109.9616; 19013, 19014); Ensenada de Muertos (23.9992, -109.8269; 5600, 5602, 5613, 5614); 0.5 km S, 6.1 km W Los Planes (23.9625, -109.9978; 19037); 1.3 km S, 0.8 km E Los Planes (23.9549, -109.9278; 19332); 3 km S, 7 km W Los Planes 23.9440, -110.0060; 19025, 19026); 3.1 km S, 4 km W Los Planes (23.9371, -109.8971; 19335, 19336, 19337); 3.7 km S, 1 km W Los Planes (23.9334, -109.9480; 19339); 4.3 km S Los Planes (23.9283, -109.9358; 15421, 15423, 18651, 18654, 18655, 18656, 18657, 18658, 18659, 18661); 4.5 km S, 1.9 km E Los Planes (23.9254, -109.9170; 18669); 5 km S, 1.6 km W Los Planes (23.9232, -109.9535; 18662, 19387, 19388); 5.7 km S, 8 km W Los Planes (23.9155,-110.0164; 19049, 19050); 6 km S, 2.8 km W Los Planes (23.9130, -109.9073; 19440, 19441, 19442, 19445); 6 km S, 1 km E Los Planes (23.9138, -109.9307; 17404); 7 km S, 8 km W Los Planes (23.9044, -110.0167; 19066, 19067, 19068); 7.4 km S, 8.6 km W Los Planes (23.8990, -110.0218; 19071, 19072, 19073); 7.5 km S, 7.6 km W Los Planes (23.9005, -110.0121; 19451, 19452, 19453, 19455); 8.7 km S, 8 km W Los Planes (23.8893, -110.0183; 19464, 19466, 19467); 9.1 km S, 2.9 km W Los Planes (23.8850, -109.9073; 19468, 19469); 9.2 km S, 3.1 km W Los Planes (23.8828, -109.9663; 19470, 19477, 19478); 10.3 km S, 7.4 km W Los Planes (23.8742, -110.0091; 19486, 19490, 19492, 19494); 10.4 km S, 5.5 km W Los Planes (23.8708, -109.9663; 19085, 19086); 10.4 km S, 6 km W Los Planes (23.8728, -109.9914; 19496, 19497); 10.6 km S, 3 km W Los Planes (23.8729, -109.9906; 19104, 19105); 11 km S, 8 km W Los Planes (23.8712, -110.0136; 19127, 19128); 11.8 km S, 0.6 km E Los Planes (23.8598, -109.9300; 19511). Haplotipo 2 (KT321929): Isla Cerralvo (24.1555, -109.8692; 16067, 16068). Haplotipo 3 (KT321930): 8.1 km N, 6.3 km E Los Planes (24.0377, -109.8729; 19304); 7.5 km S, 7.6 km W Los Planes (23.9005, -110.0121; 19460); 8.7 km S, 8 km W Los Planes (23.8893, -110.0183; 19461). Haplotipo 4 (KT321931): 8.1 km N, 6.3 km E Los Planes (24.0377, -109.8729; 19305); 6 km N, 2 km E Los Planes (24.0207, -109.9175; 19316); 5.3 km N Los Planes (24.0152, -109.9334; 19320, 19322, 19323); Ensenada de Muertos (23.9992, -109.8269; 5601, 5603, 5611); 2.5 km S Los Planes (23.9446, -109.9363; 19334); 3.7 km S, 1 km W Los Planes (23.9334, -109.9480; 19259); 4.3 km S Los Planes (23.9283, -109.9358; 15422, 18660); 4.5 km S, 1.9 km E Los Planes (23.9254, -109.9170; 18667); 5 km S, 1.6 km W Los Planes (23.9232, -109.9535; 18663, 19386); 5.7 km S, 8 km W Los Planes (23.9155, -110.0164; 19051); 6 km S, 2.8 km W Los Planes (23.9130, -109.9073; 19439, 19447); 6 km S, 1 km E Los Planes (23.9138, -109.9307; 17405); 7.5 km S, 7.6 km W Los Planes (23.9005, -110.0121; 19454, 19456); 8.7 km S, 8 km W Los Planes (23.8893, -110.0183; 19465); 9.2 km S, 3.1 km W Los Planes (23.8828, -109.9663; 19471, 19479); 10.6 km S, 3 km W Los Planes (23.8729, -109.9906; 19106); 11 km S, 3.7 km W Los Planes (23.8703, -109.9711; 19116, 19117, 19118); 11.5 km S, 8.7 km W Los Planes (23.8635, -110.0209; 17406); 11.8 km S, 0.6 km E Los Planes (23.8598, -109.9300; 19512). Haplotipo 5 (KT321932): 7 km N Los Planes (24.0261, -109.9340; 19306); 5.3 km N Los Planes (24.0152, -109.9334; 19321); 10.3 km S, 7.4 km W Los Planes (23.8742, -110.0091; 19491). Haplotipo 6 (KT321933): 4.5 km S, 1.9 km E Los Planes (23.9254, -109.9170; 18664). Haplotipo 7 (KT321934): 4.5 km S, 1.9 km E Los Planes (23.9254, -109.9170; 18665); 10.4 km S, 6 km W Los Planes (23.8728, -109.9914; 19495); 11 km S, 8 km W Los Planes (23.8712, -110.0136; 19126). Haplotipo 8 (KT321935): 3 km S, 7 km W Los Planes (23.9440, -110.0060; 19027); 4.5 km S, 1.9 km E Los Planes (23.9254, -109.9170; 18668). Haplotipo 9 (KT321936): 6 km N, 8 km W Los Planes (24.0226, -110.0146; 18999). Haplotipo 10 (KT321937): 6 km N, 2 km E Los Planes (24.0207, $-109.9175 ; 19309,19312) ; 4.3$ km S Los Planes (23.9283, -109.9358; 18653); 7.5 km S, 7.6 km W Los 
Planes (23.9005, -110.0121; 19459). Haplotipo 11 (KT321938): 6 km N, 2 km E Los Planes (24.0207, -109.9175; 19311); 0.5 km S, 6.1 km W Los Planes (23.9625, -109.9978; 19035, 19036). Haplotipo 12 (KT321939): 6 km N, 2 km E Los Planes (24.0207, -109.9175; 19317); 8.7 km S, 8 km W Los Planes (23.8893, -110.0183; 19463). Haplotipo 13 (KT321940): 4.5 km S, 1.9 km E Los Planes (23.9254, -109.9170; 18666). Haplotipo 14 (KT321941): 3.7 km S, 1 km W Los Planes (23.9334, -109.9480; 19343). Haplotipo 15 (KT321942): 4.3 km S Los Planes (23.9283, -109.9358; 18650, 18652). Haplotipo 16 (KT321943): Isla Cerralvo (24.1555, -109.8692; 233). Haplotipo 17 (KT321944): 6 km S, 2.8 km W Los Planes (23.9130, -109.9073; 19438).

Anexo 1D. Lista de ejemplares empleados en los experimentos etológicos, localidad de colecta y número de catálogo CIB.

Dominancia intraespecífica: C. siccus, $5 \mathrm{~km} \mathrm{S,} 1.6 \mathrm{~km}$ W Los Planes, B. C. S. $(23.9232 \mathrm{~N},-109.9535$ W), 22337-22341, 27290-27295, 27299-27301, 27303-27304 CIB; 6 km S, 2.8 km W Los Planes, B. C. S. (23.9130 N, -109.9073 W) 22342-22349, 27275, 27277, 27281-27283, 27285 27288-27389 CIB. Dominancia interespecífica: C. siccus, 5 km S, 1.6 km W Los Planes, B. C. S. (23.9232 N, -109.9535 W), 22336, 23090-23093, 23100-23101; 3 km S, 7 km W Los Planes, B. C. S. (23.929440 N, -110.0060 W), 23164-23166; 6 km S, 2.8 km W Los Planes, B. C. S. (23.9130 N, -109.9073 W), 22350, 27550. 2763927646 CIB). C. arenarius: 3 km N, 7.7 km W Las Paz, B.C.S (24.1689 N, -110.3895 W), cinco ejemplares capturados y liberados. C. ammophilus: $5 \mathrm{~km} \mathrm{~N}, 19.4 \mathrm{~km} \mathrm{~W} \mathrm{La} \mathrm{Paz,} \mathrm{B.} \mathrm{C.} \mathrm{S.}(24.1884$ N, -110.5030 W), cinco ejemplares capturados y liberados. C. spinatus: $5 \mathrm{~km} \mathrm{~S}, 1.6 \mathrm{~km} \mathrm{~W}$ Los Planes, B. C. S. (23.9232 N, $-109.9535 \mathrm{~W})$, conco ejemplares capturados y liberados. C. rudinoris, $5 \mathrm{~km} \mathrm{S,} 1.6 \mathrm{~km} \mathrm{~W}$ Los Planes, B. C. S. (23.9232 N, -109.9535 W), cinco ejemplares capturados y liberados. 